ISSN 2227-9717

Article

www.mdpi.com/journal/processes

\title{
Systematic Sustainable Process Design and Analysis of Biodiesel Processes
}

\section{Seyed Soheil Mansouri, Muhammad Imran Ismail, Deenesh K. Babi, Lida Simasatitkul, Jakob K. Huusom and Rafiqul Gani *}

CAPEC, Department of Chemical and Biochemical Engineering, Technical University of Denmark, Building 229, Søltofts Plads, DK-2800 Kgs. Lyngby, Denmark; E-Mails: seso@kt.dtu.dk (S.S.M.); mibi999@yahoo.com (M.I.I.); dkbabi@kt.dtu.dk (D.K.B.); por_iam@hotmail.com (L.S.); jkh@kt.dtu.dk (J.K.H.)

* Author to whom correspondence should be addressed; E-Mail: rag@kt.dtu.dk;

Tel.: +45-45-25-28-82; Fax: +45-45-93-29-06.

Received: 5 June 2013; in revised form: 27 July 2013 / Accepted: 13 August 2013 /

Published: 3 September 2013

\begin{abstract}
Biodiesel is a promising fuel alternative compared to traditional diesel obtained from conventional sources such as fossil fuel. Many flowsheet alternatives exist for the production of biodiesel and therefore it is necessary to evaluate these alternatives using defined criteria and also from process intensification opportunities. This work focuses on three main aspects that have been incorporated into a systematic computer-aided framework for sustainable process design. First, the creation of a generic superstructure, which consists of all possible process alternatives based on available technology. Second, the evaluation of this superstructure for systematic screening to obtain an appropriate base case design. This is done by first reducing the search space using a sustainability analysis, which provides key indicators for process bottlenecks of different flowsheet configurations and then by further reducing the search space by using economic evaluation and life cycle assessment. Third, the determination of sustainable design with/without process intensification using a phenomena-based synthesis/design method. A detailed step by step application of the framework is highlighted through a biodiesel production case study.
\end{abstract}

Keywords: biodiesel; superstructure; process intensification; phenomena based; simulation; design 


\section{Nomenclature}

\begin{tabular}{|c|c|}
\hline $2 \mathrm{phM}$ & 2-phase mixing \\
\hline $\mathrm{AF}$ & Accumulation factor \\
\hline$C$ & The cost function to be maximized or minimized \\
\hline $\mathrm{D}$ & Dividing \\
\hline $\mathrm{E}$ & Energy \\
\hline EWC & Energy waste cost \\
\hline FAME & Fatty acid methyl ester \\
\hline FFA & Fee fatty acid \\
\hline $\mathrm{H} / \mathrm{C}$ & Heating/Cooling \\
\hline $\mathrm{L}$ & Logical \\
\hline $\mathrm{L}$ & Liquid \\
\hline LCA & Life cycle assessment \\
\hline M & Mixing \\
\hline MIX- & Mixer \\
\hline MVA & Material value added \\
\hline MW & Molecular weight \\
\hline $\mathrm{O}$ & Operational \\
\hline PBS & Phenomena based synthesis \\
\hline $\mathrm{PC}$ & Phase contact \\
\hline PI & Process intensification \\
\hline PT & Phase transition \\
\hline $\mathrm{R}$ & Reaction \\
\hline $\mathrm{RM}$ & Raw materials \\
\hline $\mathrm{S}$ & Structural \\
\hline SPBs & Simultaneous phenomena building blocks \\
\hline TVA & Total value added \\
\hline $\mathrm{V}$ & Vapor \\
\hline$B_{1}, B_{2}$ & Matrices of constant coefficients \\
\hline$b^{l}, b^{u}$ & Upper bounds of the linear and non-linear equations \\
\hline cT- & Column-condenser \\
\hline E- & Heat exchanger \\
\hline$e_{i}$ & Utility usage \\
\hline eq. & Equivalent \\
\hline$f$ & A vector of non-linear equations \\
\hline $\mathrm{F}_{\text {obj }}$ & Objective function \\
\hline$h^{l}, h^{u}$ & Lower bounds of the linear and non-linear equations \\
\hline $\mathrm{M}_{\mathrm{id}}$ & Ideal mixing \\
\hline $\mathrm{M}_{\mathrm{rec}}$ & Rectangular flow mixing \\
\hline $\mathrm{M}_{\mathrm{tub}}$ & Tubular flow mixing \\
\hline $\mathrm{NSP}_{\max }$ & Total number of possible SPBs \\
\hline $\mathrm{Ph}_{\mathrm{BB}}$ & Total number of phenomena building blocks \\
\hline $\mathrm{Ph}_{\mathrm{E}}$ & Total number of energy transfer phenomena \\
\hline $\mathrm{Ph}_{\mathrm{M}}$ & Total number of mixing phenomena \\
\hline $\mathrm{PI}_{\mathrm{s}}$ & PI screening \\
\hline R- & Reactor \\
\hline
\end{tabular}




$\begin{array}{ll}\mathrm{rT}- & \text { Column-reboiler } \\ \mathrm{T}_{\mathrm{b}} & \text { Boiling temperature } \\ \mathrm{T}_{\mathrm{c}} & \text { Critical temperature } \\ \mathrm{T}_{\mathrm{m}} & \text { Melting temperature } \\ v^{l}, v^{u} & \text { Upper bounds and lower bounds of operational constraints } \\ \mathrm{V}_{\mathrm{m}} & \text { Molar volume } \\ \mathrm{V}_{\mathrm{VdW}} & \text { Van der Waals volume } \\ w^{l} & \text { Vectors which account for operational constraints } \\ y_{j} & \text { The vector represents } 0 / 1 \text { binary variables }\end{array}$

\section{Introduction}

Today fossil fuels make up around $80 \%$ of the global primary energy consumption, of which nearly $58 \%$ is solely used by the transportation sector [1]. Fuel consumption is growing dramatically, resulting in greenhouse gas emissions that affect global warming. Progressive depletion of conventional fossil fuels due to increasing energy consumption have led to a move towards alternative, renewable, sustainable, efficient and cost-effective energy sources and production processes with lesser emissions [2].

One of most promising fuel alternatives is biodiesel, which can be obtained from renewable resources such as palm oil. Biodiesel is a green fuel and has desirable characteristics compared to conventional diesel fuel. For example, it is non-toxic, biodegradable and has a very low concentration of sulfur. In addition it has a high cetane number (above 60 as compared to 40 for regular diesel), a high flash point $\left(<130{ }^{\circ} \mathrm{C}\right)$ and it emits $\sim 70 \%$ fewer hydrocarbons, $\sim 80 \%$ less carbon dioxide and $\sim 50 \%$ less particulates [3]. The interest in biodiesel can also be understood from its global production in recent years. Europe is currently the largest producer, while Brazil has the highest increase in production rate in the last years when compared to Europe and the United States - an increase from $736 \mathrm{~m}^{3}$ in 2005 to $2,400,000 \mathrm{~m}^{3}$ in 2010 [4].

Biodiesel can be produced from different feedstocks, which is dependent on the geographical location and climate. Common feedstocks are vegetable oils, for example, sunflower oil, rape seed oil and palm oil [5]. Vegetable oil is the oil that comes from all-vegetable sources and it can be a blend of oils from several different plant sources. Note that not all vegetable oils are edible oils. Examples of non-edible vegetable oils are oils from Jatropha curcas and Pongamia glabra (karanja) while edible vegetable oils are oils from rape seeds, palm seeds and sunflower. The most important obstacle to biodiesel industrialization and commercialization is that these feedstocks are regarded as belonging to the food-chain. Therefore, the usage of waste edible oils that can also be used for biodiesel production is recommended [6,7]. Waste edible oils are normally characterized by relatively high free fatty acid (FFA) and water contents and these have a significant effect on the transesterification reaction, whereas vegetable oils have a very low FFA content.

Biodiesel can be produced using different reaction routes, depending on the feedstocks and catalysts used. Amongst them, the homogenous/heterogeneous acid-/alkali-catalyzed transesterification, enzymatic transesterification, supercritical methanol transesterification, microwave assisted and ultrasound assisted transesterification have been reported. The most commonly used approach, however, appears to be catalytic (alkaline-based) transesterification [8,9]. Different flowsheet 
alternatives for biodiesel production exist and therefore it is important to study their sustainability issues in order to find the most promising and sustainable alternative. One way to achieve this objective is to employ a systematic computer-aided framework for sustainable process design [10-12], which provides the flexibility of evaluating/screening different flowsheet alternatives for selecting the optimal (more sustainable) design and combine it with options to evaluate opportunities for process intensification [13]. A recent review [14] on the role of process synthesis related to bio-process synthesis and design have also highlighted the need for a systematic synthesis/design framework.

West et al. [15] have assessed four biodiesel production processes that employed homogeneous acid/alkali catalysts, a heterogeneous acid catalyst and a supercritical method to convert waste vegetable oil (waste Canola oil was represented by triolein and oleic acid) into biodiesel. They showed that process employing heterogeneous acid catalyst and the supercritical method have the smallest number of unit operations and heterogeneous acid catalyzed process has the smallest capital investment.

Martin and Grossmann [16] have proposed a mathematical approach to determine the optimal production of second-generation biodiesel using waste cooking oil (they assumed that the oil can be characterized as triolein and oleic acid) and algae oil (they assumed that oleic acid with no impurities represents the oil) by simultaneous optimization and heat integration. They considered five different technologies for the transesterification of the oil (homogeneous acid- or alkali-catalyzed, heterogeneous basic-catalyzed, enzymatic, and supercritical uncatalyzed). They formulated the optimization problem as an MINLP problem. Their aim has been to perform simultaneous optimization and heat integration for the production of biodiesel from each of the different oil sources in terms of the technology to use and the operating conditions to apply. Process intensification options were, however, not included.

In this work, a systematic computer-aided hierarchical framework for combined process synthesis and process intensification is proposed for determining more sustainable process designs. This framework has been applied to identify a more sustainable process for the production of biodiesel using pure and waste palm oil as the feedstock. The choice of this feedstock is based on the information that in countries like Thailand and Malaysia, excess palm oil is available together with waste (cooking) palm oil. The objective (or target) for the more sustainable process design with/without intensification is to overcome the bottlenecks of the base case design through more sustainable process alternatives, which may include a reduction in the number of unit operations through the inclusion of intensified operations.

The framework consists of three parts where each part (sub-method) consists of its own set of calculation-analysis steps.

- Part-1 defines a superstructure. Here, information on processing routes for the product-feedstock is collected from available data and literature, which is then used to create a generic superstructure of processing routes. The superstructure describes a network of process configurations from which the optimal flowsheet can be found.

- Part-2 identifies a base case design. The superstructure from part-1 is evaluated in terms of a sustainability analysis that identifies and orders structural (process) bottlenecks within it in terms of those having the highest impact for improvement with respect to the measures of sustainability. Based on this analysis the number of process alternatives within the 
superstructure is screened and from the reduced set, a base case design is selected. This step is necessary only if a "reference" base case design is not available.

- Part-3 determines a more sustainable process design with/without process intensification. Here, the identified process bottlenecks of the base case design from part-2 are addressed through the generation of new more sustainable alternatives that target resolving the identified bottlenecks. In order to apply the phenomena based process intensification, the base case design is represented in terms of tasks (operations) that need to be performed and the phenomena associated with each task are then identified. Applying the phenomena based method [13], new process alternatives with/without PI-options are generated. These are then further reduced through economic and life cycle assessment (LCA) analysis to determine the most promising alternative that best matches the specified design targets, thereby improving the performance criteria.

\section{Sustainable Design and Intensification Framework}

The process synthesis problem is represented mathematically by Equations (1-8). Equation (1) represents the objective function, which can either be maximized or minimized. Equations $(2,3)$ define a system of linear and non-linear equations, for example, mass and energy balance (algebraic) equations representing a steady state process model. Equations $(4,5)$ represent the physical constraints and design specifications, respectively; and Equation (6), because process intensification is also included in the process synthesis problem, represents a set of constraints that the intensified process must satisfy [13]. Equations $(7,8)$ represent and define the bounds on the design variables, $x$ (real) and decision variables y (binary-integer), respectively.

$$
\begin{gathered}
\min C=C(x, y, d, z, \Theta) \\
\text { s.t. } \\
g(x, z, \Theta)=0 \\
f(x, y, d, z, \Theta)=0 \\
b^{l} \leq B_{1} x+B_{2} y \leq b^{u} \\
h^{l} \leq h(x, y) \leq h^{u} \\
v^{l} \leq v(x, y) \leq v^{u} \\
w^{l} \leq u(x, y) \leq v^{u} \\
y_{j}=0 / 1, j=1,2, \ldots n_{y}, x \geq 0
\end{gathered}
$$

The optimization problem given by Equations (1-8) represents a MINLP problem, which can be difficult to solve if the process model together with its constitutive equations are highly non-linear. The size of the MINLP problem may also be an issue. In order to manage this complexity, an efficient and systematic solution approach is used where the problem is decomposed into a set of sub-problems that are solved according to pre-defined calculation order. This method is referred to as the decomposition based solution method [17]. Most of the sub-problems require bounded solution of a sub-set of equations. The final sub-problem is solved as a set of NLP or MINLP. Equation (4) is used to find the feasible combinations of phenomena and/or flowsheets, the generated combinations are 
reduced using physical and logical constraints (Equation (4)). The set of feasible phenomena combinations are then used to generate process flowsheet alternatives from which the feasible ones are identified by simultaneously solving the process model equations (Equations (2-5)) and operational constraints (Equation (7)). The feasible alternatives are then evaluated using a set of performance related constraints (Equation (6)). For the surviving process alternatives, the objective function (Equation (1)) is calculated and ordered. The highest or the lowest can be easily located. This is the "generate and test" option. Alternatively, if the number of feasible alternatives is not too high, a welldefined MINLP problem for a reduced size of the vector $y$ is solved. In another variation, a set of NLPs for a fixed set of y can also be solved. The obtained sustainable process flowsheet is the best according to the problem definition, the selected performance criteria, constraints, availability of data, parameters and models [13]. A global optimal solution cannot be guaranteed with this method. Note that in this work only the "generate and test" option has been tested.

Figure 1 illustrates work-flow of the three-part systematic and computer aided framework for process design, with/without process intensification.

Figure 1. Sustainable design and intensification framework.

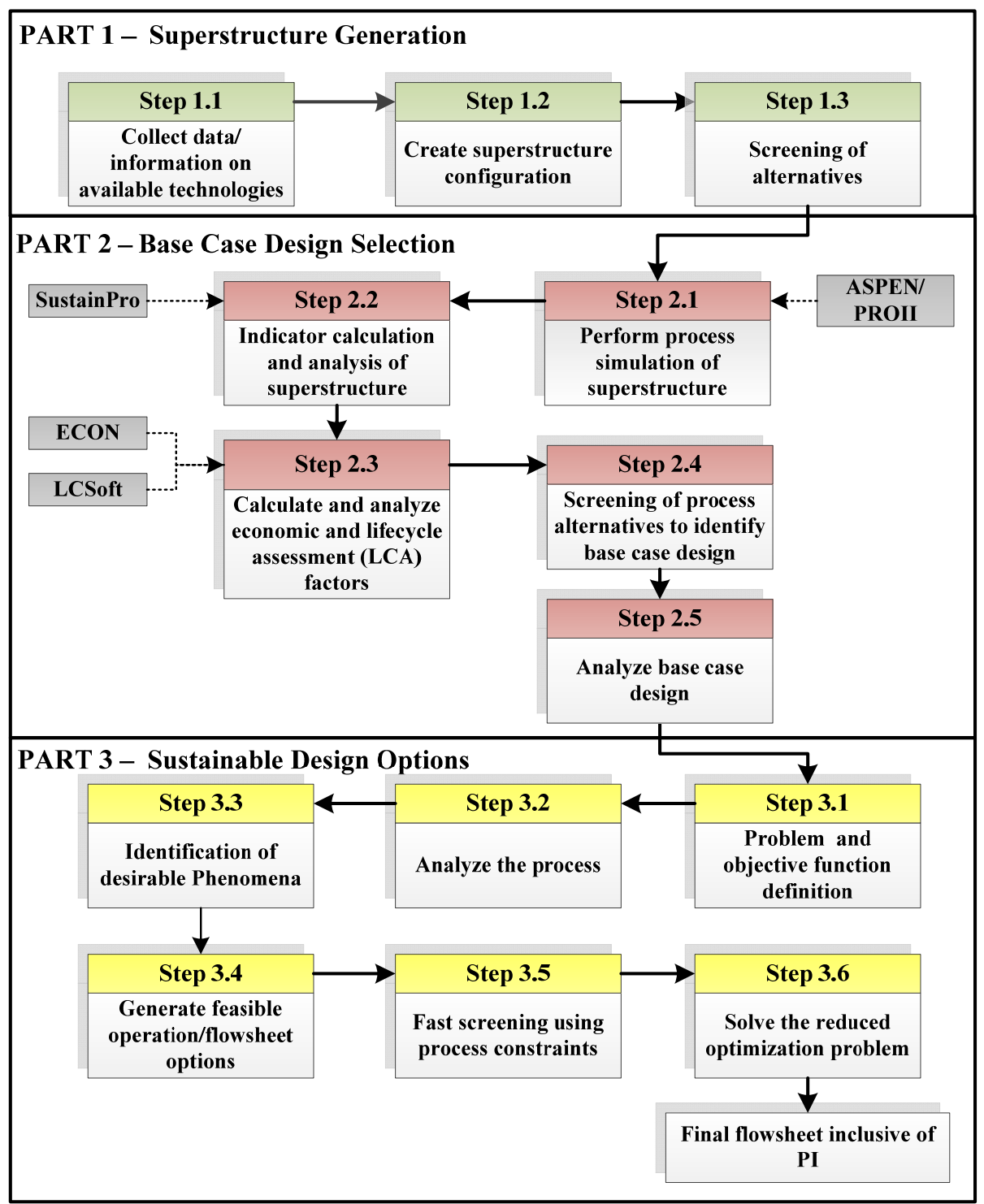




\subsection{Part 1-Superstructure Generation}

\subsubsection{Step 1.1: Collect Data/Information on Available Technologies}

The objective of this step is to collect data/information on feedstocks, processing steps, products, catalysts, reaction conversions, etc., so that a superstructure of process alternatives can be generated.

\subsubsection{Step 1.2: Create Superstructure Configuration}

Using the data from step 1.1 and relating tasks to processing routes and unit operations to tasks, a superstructure is created. Each task may involve more than one unit operation and each processing route may involve more than one task. The resulting superstructure is generic, and represents all possible flowsheet alternatives. At this stage the supersctructure has M1 flowsheet alternatives.

\subsubsection{Step 1.3: Screening of Alternatives}

The objective here is to simplify the superstructure from step 1.2 by employing the screening method also used by Simasatitkul et al. [9]. The screening method is divided into four sub-steps. First, the number of alternatives is reduced based on the type of feedstock where the criteria for selection are their availability and the cost of the raw materials. Second, the number of the processing routes is screened based on productivity of the catalyst. Since the productivity depends on the type of catalysts and operating conditions, the process that gives the highest productivity of main product for each catalyst type is only retained. Third, the number of alternatives is further reduced with respect to alternative downstream separation routes employing thermodynamic insights $[18,19]$. Here the number of separation tasks are determined first from the number of compounds present in the reactor effluent and the number of compounds to be recovered. Next, for each separation task, the ratios of pure compound properties of adjacent binary pair of compounds within the system are calculated. If the ratios are far from unity, the separation task can be linked to a corresponding separation process. For example, if for pair A-B, the ratio of vapor pressures is high, then separation of A-B (provided they do not form azeotrope) by distillation is feasible. Similarly, for the same pair, if the ratio of molar volumes is high, separation by pervaporation may also be feasible. This data would generate a very large number of alternatives. However, by adding the condition that for each separation task only the process that employs the largest available driving force would be employed, the number of alternatives is reduced significantly. In the final step, the alternatives are screened in terms of limitations of the separation technique (process). For example, separation by adsorption is removed if the temperature of operation is too high for the known adsorbents that are usually quite sensitive to the temperature, or, a suitable adsorbent could not be found. Membrane-based separation is limited by flux and fouling problems. At the end of this step, the number of feasible flowsheet alternatives without PI-options is reduced to $\mathrm{M} 2<\mathrm{M} 1$. 


\subsection{Part 2-Base Case Design Selection}

\subsubsection{Step 2.1: Perform Process Simulation of Superstructure}

In this step the superstructure representing the M2 flowsheets is simulated through a process simulator with appropriate choices of process and thermodynamic models. For phase equilibrium calculations involving the separation processes, an appropriate equilibrium constant model (a model for the liquid phase activity and a model for vapor phase fugacity) needs to be selected (for example, the NRTL or UNIQUAC models for liquid phase activity). The reactors are modeled as simple stoichiometric conversion reactors while for solid separations a simple compound splitter is employed. For separations involving vapor-liquid or liquid-liquid equilibrium, the appropriate unit operation model together with the selected equilibrium constant model is needed.

The total superstructure is simulated by setting all binary variables to 1 and allowing equal split for all split streams. This ensures no bias for any specific route and all alternatives are evaluated on the same basis. There could be other ways to perform this simultaneous simulation of the total superstructure. For different types of catalysts, different reactors with conversions obtained from published reaction kinetics data are used. The result from this step is a stream summary, at steady state, consisting of temperature, pressure, compound-flows, enthalpy, etc., for all streams in the superstructure as well as the duties for all equipments requiring energy addition/removal.

Tools: For process simulation PRO/II, Aspen, ICAS or any appropriate process simulation software.

\subsubsection{Step 2.2: Indicator Calculation and Analysis of Superstructure}

In this step steady state mass and energy balance data from Step 2.1 are used as input for a sustainability analysis, which is based on the method of Carvalho et al. [10]. The sustainability analysis uses an indicator-based methodology where a set of calculated closed- and open-path indicators are used to identify the structural bottlenecks within any process flowsheet (in this case, the superstructure). Through an open-path, mass (of a compound) and energy (carried by a compound) come in and go out of the system (process), while in a closed-path, they go around in cycles without going out (they represent recycle streams). The indicators therefore indicate whether a material or its energy equivalent loose value as they leave a process or if a large amount go around in cycles without going out. Through the values obtained for the indicators, it is possible to identify the location within the process where the mass/energy "path" faces "barriers" with respect to costs, benefits and accumulation [10]. Through a sensitivity analysis, the process (design) variables that have the largest effect on the indicators are identified and the needed change in the indicators is set as a design target. Since the indicators are directly related to the sustainability metrics, achieving the design target also means a more sustainable process has been found. This also means that the carbon footprint would be reduced and the profit would be increased.

The details of the work-flow and the sustainability analysis method can be found in a series of articles published by Carvalho et al. [10-12]. Using the sustainability analysis, the number of feasible flowsheet alternatives within the superstructure is further reduced (to M3 < M2) by selecting those having the lowest sustainable impact based on the following sustainability indicators: 
1. Material value added (MVA): This indicator gives the value added between the entrance and the exit of a given compound, that is, the value generated or lost between the start and the end point of an open-path. Negative values of this indicator show that the compound has lost its value in this open-path and therefore point to a potential for improvement.

2. Energy and waste cost (EWC): This indicator is applied to both open- and closed-paths. It takes into account the energy costs (EC) and the costs related with the compound treatment (WC). The value of EWC represents the maximum theoretical amount of energy that can be saved in each path within the process. High values of this indicator show high consumption of energy and waste costs and therefore these paths should be considered in order to reduce the indicator value.

3. Total value added (TVA): This indicator describes the economic influence of a compound in a given path and is the difference between MVA and EWC. Negative values of this indicator show high potential for improvements in terms of decrease in the variable costs.

4. Accumulation factor (AF): This indicator determines the accumulative behavior of the compounds in the closed-paths. This corresponds to the amount that is recycled relative to the input to the process and not the inventory. High values of this indicator show high potentials for improvements.

It should be noted that having the indicator values is not enough. It is necessary to perform a sensitivity analysis to identify the operation requiring the least change to obtain the largest effect in the correct direction for the indicator. Also, the effect in the indicator needs to be evaluated against the improvement in the sustainability metrics. The result of this analysis is the identification of a target indicator with a target value for improvement that can be achieved through minimum changes in one or more operational variables related to the indicator. Based on this analysis, the indicators are ordered according to a scoring system [10]. That is, the indicators are ranked (high, medium, low) in terms of their potential to improve the process (or make it more sustainable).

Tools: The method developed by Carvalho et al. [10,11] and its corresponding software-tool, SustainPro [12].

\subsubsection{Step 2.3: Calculate and Analyze Economic and Lifecycle Assessment (LCA) Factors}

In this step the remaining flowsheet alternatives (M3) from Step 2.2 are further analyzed using an economic and LCA evaluation. The economic evaluation provides an estimate of the operational cost and the LCA provides the environmental impact of the reduced flowsheet alternatives, for example, the carbon footprint.

Tools: For the economic evaluation: ECON [20], which is based on the economic evaluation model given in [21]. For the LCA: LCSoft [22], which uses US-EPA and IPCC emission factors to calculate the environmental impact and assesses the environmental impact and carbon footprint of a process.

\subsubsection{Step 2.4: Screen Process Alternatives to Identify the Base Case Design}

In this step the results from Step 2.3 are used for further reduction of the remaining flowsheet alternatives from Step 2.2 based on the economic and LCA evaluation. The flowsheet alternative that matches the specified production constraints with the least bottlenecks is selected as the base case design. 


\subsubsection{Step 2.5: Analyze Base Case Design}

The objective in this step is to identify the potential bottlenecks through a more detailed and rigorous simulation and indicator based analysis. That is, the input flowrates and some process design variables are re-evaluated because the condition of all binary variables equal to unity and all split streams being equal are no longer valid. Therefore, the measures by which the new alternatives would be compared to establish the more sustainable designs are re-calculated in this step for the base-case design. These measures are the sustainability metrics (obtained through SustainPro), economic measures (obtained through ECON) and LCA factors (obtained through LCSoft). These measures will be used to set the design targets for Part 3.

\subsection{Part 3-Sustainable Design Options}

Compared to the base-case design of step 2.5, to achieve a more sustainable process design, phenomena based synthesis/design intensification method (PBS) is applied. A brief explanation of the method is presented here and the reader can obtain further details from Lutze et al. [13]. The method operates at the phenomena level and the concept is similar to that of computer-aided molecular design (CAMD) where groups of atoms are used as building blocks to generate new as well as known molecules with desired (target) properties [13].

Figure 2. Phenomena-based Process intensification (PI) concepts using computer-aided molecular design (CAMD).

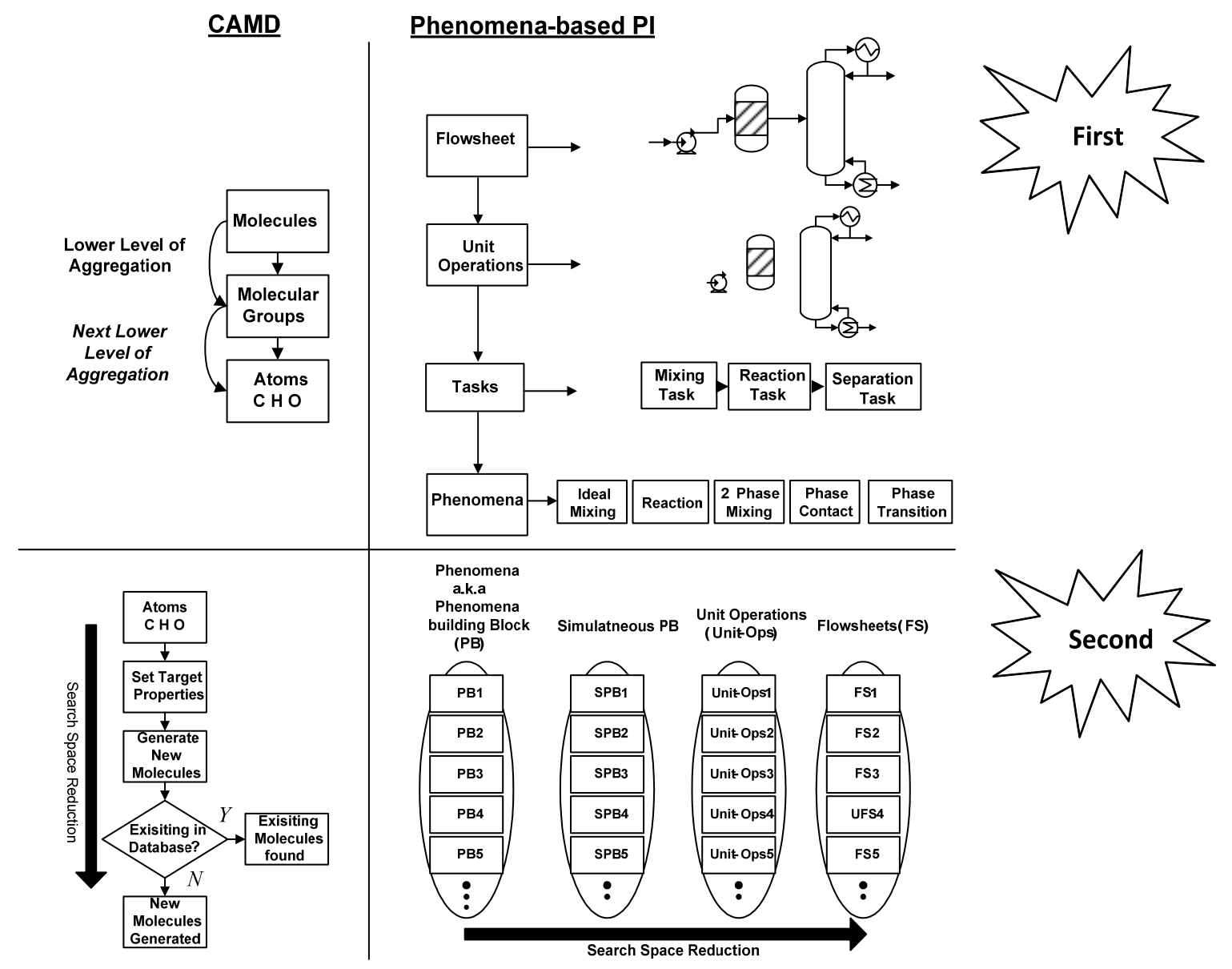


In the same way the PBS method also operates at different levels of aggregation where the flowsheet is represented in terms of unit operations from which the necessary tasks are identified. For each task, the involved phenomena are identified. Therefore, just as groups of atoms can be joined to form molecules, groups of phenomena can be joined to form existing as well as new tasks. In a similar way, groups of tasks can be joined to form operations and groups of operations can be joined to form process flowsheets. The number of alternatives that can be generated increases by going to a lower level of aggregation, just as in the case of molecular design. This concept is illustrated in Figure 2.

The phenomena currently considered are classified into eight different classes. They are: mixing-M (mass flow within one or several phases), phase contact-PC (the contact and resistances at phase boundaries of phases), phase transition-PT (mass transfer of compounds between two phases), phase change-2phM (state change of a complete stream at no phase transition), phase separation-PS (the degree of separation of two phases), reaction-R (change in mass of a compound or compounds generated or consumed between inlet and outlet), energy transfer-H/C (energy transfer between sources and sinks of energy) and stream dividing-D (division of a stream into two or more streams).

\subsubsection{Step 3.1: Problem and Objective Function Definition}

In this step the synthesis/design problem and objective function is defined together with the process boundaries, underlying assumptions, and the performance metrics for screening PI options.

\subsubsection{Step 3.2: Analyze the Process}

In this step, the base case design is analyzed in order to further identify/classify the process bottlenecks through a knowledge-based and a model-based approach. All mass and energy data are collected from the rigorous simulation of the base case design and the flowsheet is transformed into a task and phenomena based flowsheet in order to decouple the analysis from physical unit operations. The identified process bottlenecks are subsequently linked to corresponding phenomena and tasks inside and outside of the unit operation in which they occur. For analyzing the properties of the compounds in the system in general the method developed by Jaksland et al. [18] based on thermodynamic insights is used.

\subsubsection{Step 3.3: Identification of Desirable Phenomena}

In this step additional phenomena for synthesis of flowsheets, which match the targets defined in Step 3.1 and thereby improve the process performance of the necessary phenomena (identified in Step 3.2) are selected. That is, the identified process bottlenecks and the corresponding phenomena and tasks are used to identify tasks and phenomena that need to be improved to achieve the desired performance. For the selection of suitable (desirable) phenomena, property analysis of single compound and mixtures of compounds as well as reactions in the system are needed. From the set of suitable phenomena the most promising phenomena are selected. However, some phenomena cannot be used on their own; hence, additional accompanying phenomena are selected. Finally, the operating window of all identified phenomena in the search space is determined. These are needed as input for the next step. 


\subsubsection{Step 3.4: Generate Feasible Operation/Flowsheet Options}

In this step all phenomena based process options are generated. They are screened according to logical and structural constraints. The input to this step is the initial search space of identified phenomena and its corresponding operating windows. Next, all phenomena are connected to form feasible simultaneous phenomena building blocks (SPBs). Note that SPBs are connected to form operations, which are translated into unit operations, which are then combined to form flowsheet alternatives. Not all SPBs when connected to form operations are feasible and structurally promising and therefore, screening based on logical and structural constraints, which were defined in Step 3.1 is performed again to obtain the feasible set.

\subsubsection{Step 3.5: Fast Screening Using Process Constraints}

In this step the feasible SPBs are connected to form the feasible flowsheet alternatives. The flowsheet alternatives are then screened in terms of operational constraints and performance criteria at the unit operation level using process simulation and analysis tools.

\subsubsection{Step 3.6: Solve the Reduced Optimization Problem}

In this step the most promising feasible flowsheet alternatives inclusive of PI are identified. This is achieved by optimization of the objective function with respect to the full mathematical model simultaneously for each remaining flowsheet alternatives and ranking all options by their corresponding performance.

\section{Case Study}

The application of the framework is highlighted through a case study. Due to the emerging demand for sustainable fuels from renewable resources in order to have lower environmental impacts, production of biodiesel was selected as a case study highlighting the application of the computer-aided framework. Throughout the application of the framework on the biodiesel production process, several software and computer-aided methods and tools have been employed, as listed in Table 1.

Table 1. Type of software used in the case study.

\begin{tabular}{llc}
\hline \multicolumn{1}{c}{ Software } & \multicolumn{1}{c}{ Application } & References \\
\hline PRO/II & Process simulation & {$[23]$} \\
Aspen Hysys & Process simulation & {$[24]$} \\
SustainPro & Sustainability analysis & {$[10-12]$} \\
ECON & Economic analysis & {$[20,21]$} \\
LCSoft & Life cycle assessment & {$[22]$} \\
ICAS-ProPred & Chemical and physical properties & {$[25]$} \\
\hline
\end{tabular}




\subsection{Part-1: Superstructure Generation}

\subsubsection{Step 1.1: Collect Data/Information on Available Technologies}

Available data for several biodiesel processing routes were collected from reported technologies in the literature. The different catalysts applied for biodiesel production can be classified in terms of alkali catalyst, acid catalyst, solid base catalyst, solid acid catalyst and enzyme catalyst [9]. Different types of catalysts were considered to design multiple processing routes and they are given in Table 2 .

Table 2. List of catalysts that may be used for production of biodiesel.

\begin{tabular}{|c|c|c|c|c|c|c|c|c|}
\hline Raw material & Alcohol & Catalyst & Ratio & $\begin{array}{c}\text { Temperature } \\
\left({ }^{\circ} \mathrm{C}\right) \\
\end{array}$ & $\begin{array}{c}\text { Pressure } \\
\text { (atm) }\end{array}$ & $\begin{array}{c}\text { Residence } \\
\text { time (h) }\end{array}$ & $\begin{array}{c}\text { Conversion } \\
(\%) \\
\end{array}$ & References \\
\hline Palm oil & Methanol & KOH 1 wt.\% & $6: 1$ & 60 & 1 & - & 95 & [26] \\
\hline Waste oil & Methanol & KOH 1 wt.\% & $50: 1$ & 80 & 1 & - & 97 & {$[26]$} \\
\hline Waste oil & Methanol & KOH 1 wt.\% & $6: 1$ & 70 & 1 & - & 95 & [26] \\
\hline Palm oil & Methanol & $\mathrm{KOH}$ & $3: 1$ & - & 1 & - & 99.8 & {$[27]$} \\
\hline Palm oil & Methanol & $\mathrm{KOH}$ & - & - & 1 & - & 99.7 & [27] \\
\hline Palm oil & Methanol & KOH 1 wt.\% & $6: 1$ & 60 & 1 & 1 & 82.5 & [28] \\
\hline Waste cooking oil & Methanol & $\mathrm{H}_{2} \mathrm{SO}_{4} 4$ wt. $\%$ & $20: 1$ & 95 & 1 & 10 & 90 & [29] \\
\hline Waste cooking oil & Methanol & $\begin{array}{c}\text { Carbon based } \\
\text { catalyst } 10 \text { wt.\% }\end{array}$ & $30: 1$ & 80 & 1 & 8 & Yield $=92$ & {$[30]$} \\
\hline Palm oil & Methanol & $\mathrm{NaOH} 0.2$ wt.\% & $6: 1$ & 60 & 1 & 1.33 & 94.3 & [31] \\
\hline Palm oil & Methanol & $\begin{array}{c}\kappa \text {-carrageenan } \\
52.5 \text { wt. } \%\end{array}$ & $7: 1$ & 30 & 1 & 72 & 99 & {$[32]$} \\
\hline Palm oil & Methanol & $\begin{array}{c}20 \% w / w \\
\text { DTPA/Clay, } 5 \%\end{array}$ & $15: 1$ & 170 & 17 & 6 & 94 & {$[33]$} \\
\hline Palm oil & - & $\begin{array}{c}\text { Immobilized } \\
\text { lipase (Candida } \\
\text { rugosa) }\end{array}$ & $\begin{array}{c}3.3 \% \\
v / v\end{array}$ & 55 & 1 & 6 & Yield $=82$ & [34] \\
\hline
\end{tabular}

\subsubsection{Step 1.2: Create Superstructure Configuration}

By using the information from Step 1.1, a generic superstructure of processing routes was created (see Figure 3). It describes a network of configurations representing multiple flowsheets. In principle, hundreds of flowsheet alternatives can be generated for the biodiesel production from this superstructure $(M 1=14256)$. Five main stages/tasks are identified for biodiesel production from waste oil and vegetable oil: feed, reaction, separation 1, separation 2 and separation 3. A pretreatment section has been considered as a black-box, that is, given the raw material resource, the output is the liquid raw material needed for the conversion step (reaction section). For the reaction section, alkali- and acid-catalyzed (homogeneous and heterogeneous), enzymatic and supercritical methanol transesterification are considered and for the separation, methanol recovery and purification of fatty acid methyl ester (FAME) and glycerol are considered. The separation task is divided into three sub-tasks: Separation-1 for methanol recovery; Separation-2 for water washing and neutralization; and, Separation-3 for biodiesel purification and glycerol recovery. The throughput for each unit is determined for each section. For example, in the separation-1 section, the input is determined from the 
output from the reactor and the output is determined based on the input in the separation- 2 section or if recycle exists, a methanol recovery recycle stream is needed. The type of separation task was selected based on available information in the literature.

Figure 3. Closed- and open-paths that were identified as major bottlenecks in the superstructure.

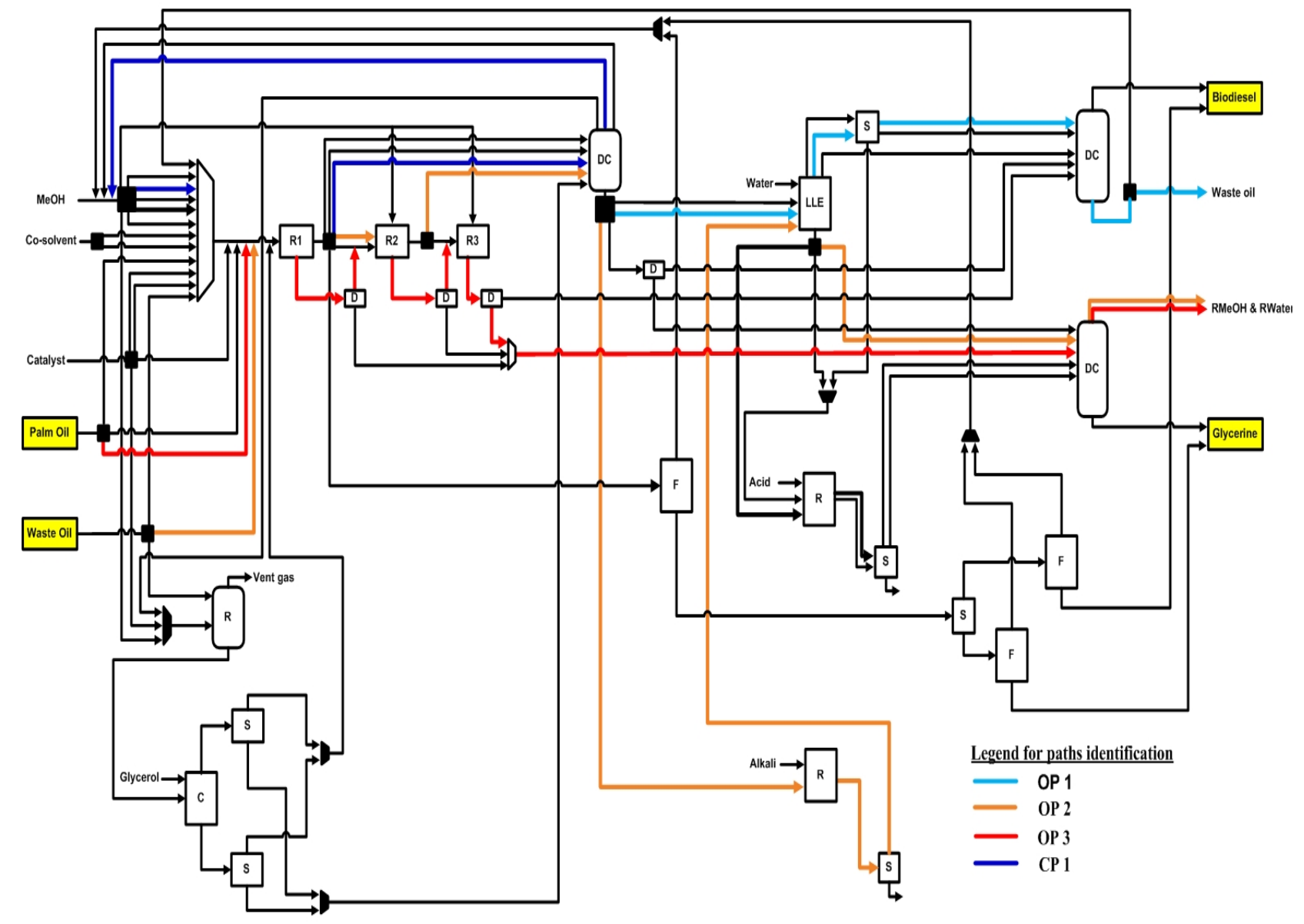

\subsubsection{Step 1.3: Screening of Alternatives}

The superstructure is analyzed and the alternatives have been screened based on criteria that are also used by Simasatitkul et al. [9]. In this work, the feedstocks considered are palm oil and waste (cooking) palm oil. Besides, the productivity of the catalyst was also used as a part of the screening procedure where the processes that only give the highest productivity of biodiesel are retained. The reduction of the superstructure for the highest separation task is carried out as well as the limitations of the separation technique.

In order to reduce the size of the combinatorial problem, the following assumptions were made:

1. The different types of the same group of catalysts were not considered, for example, for all alkaline catalyst options, only one option was considered: the alkali-catalyzed transesterification.

2. The triglycerides were only assumed to be Triolein.

3. The design was based on the use of palm oil and waste palm oil as feedstock with low free fatty acid content ( $5 \%$ FFA).

4. The total operation time is assumed to be 350 days per year. 
5. The following reactions were considered to represent transesterification and esterification steps [35]:

Reaction 1: Esterification

Oleic acid + Methanol $\rightarrow$ Methyl oleate + Water

Reaction 2: Transesterification

Triolein + Methanol $\rightarrow$ Methyl oleate + Glycerol

Finally, the superstructure was reduced to six process configurations to be considered in the next step of the framework.

\subsection{Part-2: Base Case Design}

\subsubsection{Step 2.1: Perform Process Simulation of Superstructure}

In this step the superstructure of feasible flowsheet combinations (M2 =6) for producing biodiesel was simulated for all processing routes in order to obtain steady state mass and energy balance data needed in the next step. The flowsheet alternatives were simulated simultaneously by setting all binary variables to unity, by equally dividing all split streams and by using different reactors for different catalyst types (modeled by their different conversion values). The interested reader can obtain the total simulated superstructure flowsheet, the corresponding computed stream summaries from the simulator and associated details from the corresponding author.

The feed to the transesterification reactor and the operating conditions for each reactor are different, but because different reactors have been used, the superstructure can indeed be simulated simultaneously. For example, the reaction in one of the alkali catalyzed processes was carried out with a 6:1 molar ratio of methanol to oil while in the enzymatic processes the molar ratio was $3: 1$. In addition, the enzymatic process used immobilized enzyme catalyst while alkali catalyzed process used sodium hydroxide as the catalyst.

All data needed for input to the simulation, for example, kinetic data and product recoveries were obtained from collected data (from Step 1.1). The chemical composition of biodiesel is dependent upon feedstock from which it is produced, as the feedstocks such as palm oil and waste oil of differing origin have dissimiliar fatty acid composition. The compounds taken into account in the simulation are taken based on the average of palm oil and waste palm oil composition available in the literature. Typical fatty acid composition for palm oil and waste oil are given in Table 3. Oleic acid is the major fatty acid present in palm oil and also in waste palm oil. To reduce the complexity of the simulation problem, glycerol trioleate (triolein) is selected to represent the palm oil feedstock for tryglycerides, while the FFA is represented by oleic acid. Based on the selected compound, the fatty acid methyl esters (FAME) are represented by methyl oleate (moleate) as the biodiesel product. The UNIQUAC model based phase equilibrium constant was employed for phase equilibrium calculations. Missing pure compound property data were generated through ICAS-ProPred [25]. The PRO/II commercial process simulation [23] was used to perform the steady state process simulation. The detailed process data for the biodiesel production were obtained through process simulation (using PRO/II) and formed the basis for design decisions to obtain a base case design. For the simulation of this superstructure, the total number of equipment considered was 99 units with 154 streams and 6 compounds. 
The generated steady state simulation data included mass/molar flowrates, temperature, pressure and enthalpy values for all streams in the superstructure, which are then used for the indicator based sustainability analysis in the next step.

Table 3. Typical fatty acid composition.

\begin{tabular}{lcc}
\hline Composition & Palm oil [36] & Waste oil [37] \\
\hline Myristic acid & $0.5-2.0$ & - \\
Palmitic acid & $32-45$ & 20.4 \\
Stearic acid & $2.0-7.0$ & 4.8 \\
Oleic acid & $38.0-52.0$ & 52.9 \\
Linoleic acid & $5.0-11.0$ & 13.5 \\
Others & - & 7.6 \\
\hline
\end{tabular}

\subsubsection{Step 2.2: Indicator Calculation and Analysis of Superstructure}

The steady state mass and energy data obtained from Step 2.1 are used here. An example of results for the sustainability analysis is shown in Tables 4 and 5 for the open- and closed-paths, respectively.

Table 4. The main open-paths in the superstructure that were identified as bottlenecks in terms of material value added (MVA), energy and waste cost (EWC), total value added (TVA) indicators.

\begin{tabular}{cccccc}
\hline Path & Compound & Flowrate $(\mathbf{k g} / \mathbf{h})$ & MVA $\left(\mathbf{1 0}^{\mathbf{3}} \mathbf{\$} / \mathbf{y}\right)$ & EWC $\left(\mathbf{1 0}^{\mathbf{3}} \mathbf{\$} / \mathbf{y}\right)$ & TVA $\left(\mathbf{1 0}^{\mathbf{3}} \mathbf{\$} / \mathbf{y}\right)$ \\
\hline OP 1 & $\mathrm{H}_{2} \mathrm{O}$ & 11.7 & -57.0 & 2.7 & -59.8 \\
OP 2 & Methanol & 8.2 & -55.3 & 3148.4 & 3093.1 \\
OP 3 & $\mathrm{H}_{2} \mathrm{O}$ & 6.9 & -34.1 & 26.8 & -60.9 \\
\hline
\end{tabular}

Table 5. The main closed-paths in the superstructure that were identified as process bottlenecks in terms of EWC and accumulation factor (AF) indicators.

\begin{tabular}{cccccc}
\hline Path & Compound & Flowrate $(\mathbf{k g} / \mathbf{h})$ & $\mathbf{E W C ~}\left(\mathbf{1 0}^{\mathbf{3}} \mathbf{\$} / \mathbf{y}\right)$ & $\mathbf{A F}\left(\mathbf{1 0}^{\mathbf{3}} \mathbf{\$} / \mathbf{y}\right)$ & Score $^{*}$ \\
\hline CP1 & Methanol & 3.2 & 2671.3 & 1.1 & High \\
\hline \multicolumn{5}{c}{ * a high score indicates a high potential for change. }
\end{tabular}

It can be seen in Table 4 that there is a high material loss ( - ve values) as well as energy consumption (+ ve values) of water and methanol in the given open paths. Furthermore, high energy consumption is also observed for methanol in the given closed-path in Table 5. In the same table, the accumulation factor (AF) is also high, which means that there is a high potential for improvement in this path. It should be noted that the paths having the higher values in terms of sustainability metrics have been considered as the bottleneck in the superstructure as presented in Figure 3.

Therefore, this information has been used to identify the path that leads to an optimal processing route. Carvalho et al. [11] explained that the lower positive value of the metric indicates that either the impact of the process is less or the output of process is more. 


\subsubsection{Step 2.3: Calculate and Analyze Economic and Lifecycle Assessment (LCA) Factors}

The remaining flowsheet alternatives from Step 2.2 were further analyzed using an economic and LCA evaluation.

In the biodiesel production process, heating, cooling and electricity are the main drivers for operating cost. The main utilities for heating/cooling are steam and cooling water, respectively. These are used by heat exchangers, reboilers, and condensers that are present in the flowsheet. The units that have a high utility cost relative to other units are identified as process bottlenecks in terms of operating cost. In this analysis, it was found that the reboiler of the columns to recover methanol, and biodiesel as well as the heat exchangers have the largest utility costs in the process. From Figure 4 it can be noted that heat exchangers E-110 and E-111 and the reboiler of column rT-108 have the largest utility costs in the process that employs an acid-catalyst for converting a feedstock of waste cooking oil. Therefore, these units were identified as process bottlenecks in terms of high energy consumption.

Figure 4. Percentage of the total utility costs with respect to each activity/unit operation.

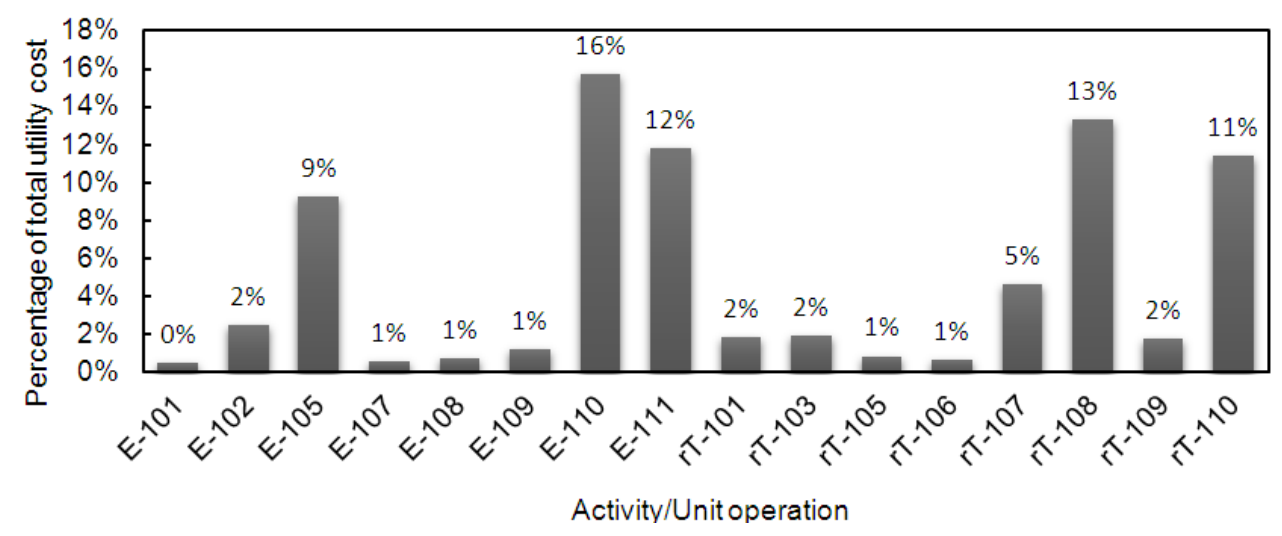

Life cycle assessment (LCA) was used to evaluate the inputs and outputs of the processes with respect to their carbon footprint and the unit operations that had a large carbon footprint relative to other units were identified as process bottlenecks. The environment impacts in terms of carbon footprint $\left(\mathrm{CO}_{2}\right.$ equivalent $)$ are presented in Figure 5. The process equipment with the highest carbon footprint is highlighted in black in this figure. For example, rT-T7 corresponds to the reboiler of the distillation column in the acid-catalyzed process for pretreatment of waste cooking oil.

Figure 5. The carbon foot prints of different unit operations in the most promising processing routes.

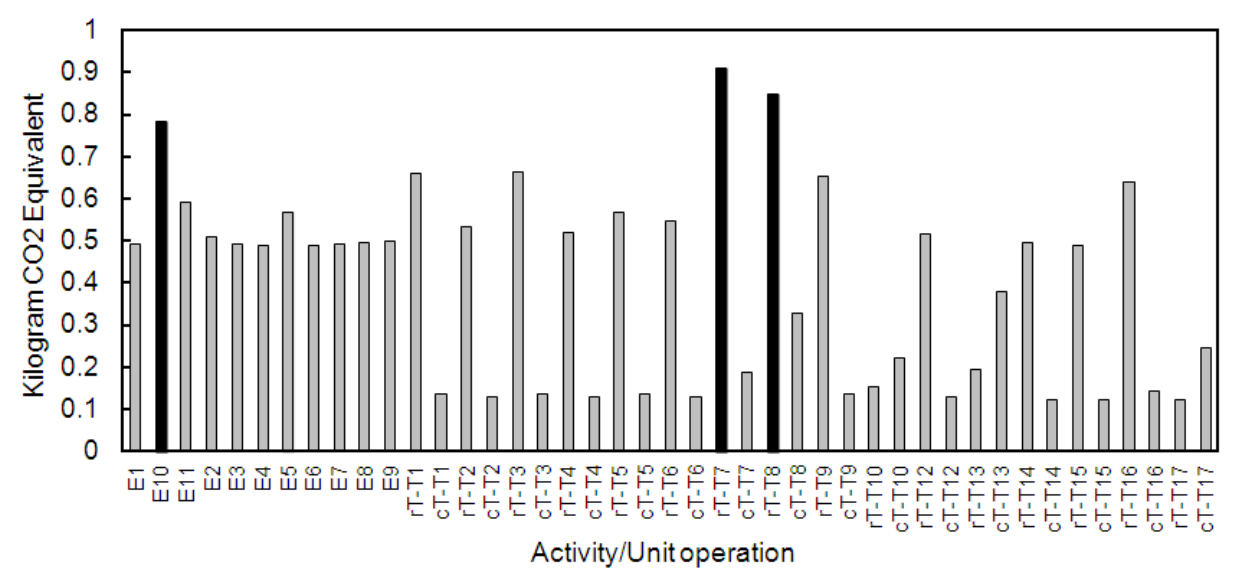




\subsubsection{Step 2.4: Screening of Alternatives to Identify Base Case Design}

An example of comparison of the sustainability metrics in two processing routes obtained from the superstructure in order to reduce the search space is presented in Table 6. Here, the considered criteria for screening were the utility costs and carbon footprint for enzymatic catalyzed process (processing route 1) and supercritical methanol process (processing route 2). From Table 6, it can be seen that the processing route 1 is better in terms of carbon footprint and total utility cost. Processing route 2 operates at high temperature and pressure, resulting in higher utility consumption and the total amount of $\mathrm{CO}_{2}$ emitted. Therefore, processing route 2 is eliminated and not considered further.

Table 6. An example of comparison of the sustainability metrics in two processing routes.

\begin{tabular}{lcc}
\hline \multicolumn{1}{c}{ Sustainability metric } & Processing route 1 & Processing route 2 \\
\hline Total $\mathrm{kg} \mathrm{CO}_{2}$ Equivalent & 1.0447 & 1.0755 \\
Total utility costs $(\$)$ & $2,350,000$ & $2,680,000$ \\
\hline
\end{tabular}

The feasible alternative selected as the base case design is presented in Figure 6 . The base case design was selected on the basis of having the least process bottlenecks (and likely operational costs) and carbon footprint. This alternative uses waste cooking palm oil as the feed over an enzyme as the catalyst [31]. The enzyme catalyzed process is recommended since it has several advantages over homogeneous catalysts, for example, high selectivity, lower energy consumption because of low temperature operation and high product yield.

Biodiesel is produced as the main product and glycerol as a value-added byproduct. There are 1 reactor, 4 distillation columns, 2 flash drums and 2 separators together with several heat exchangers and pumps in the process. Methanol is recovered throughout the process and is recycled to the feed stream by three recycle loops.

Figure 6. Biodiesel production process with glycerol as a value-added by product obtained from the superstructure which is the base case design.

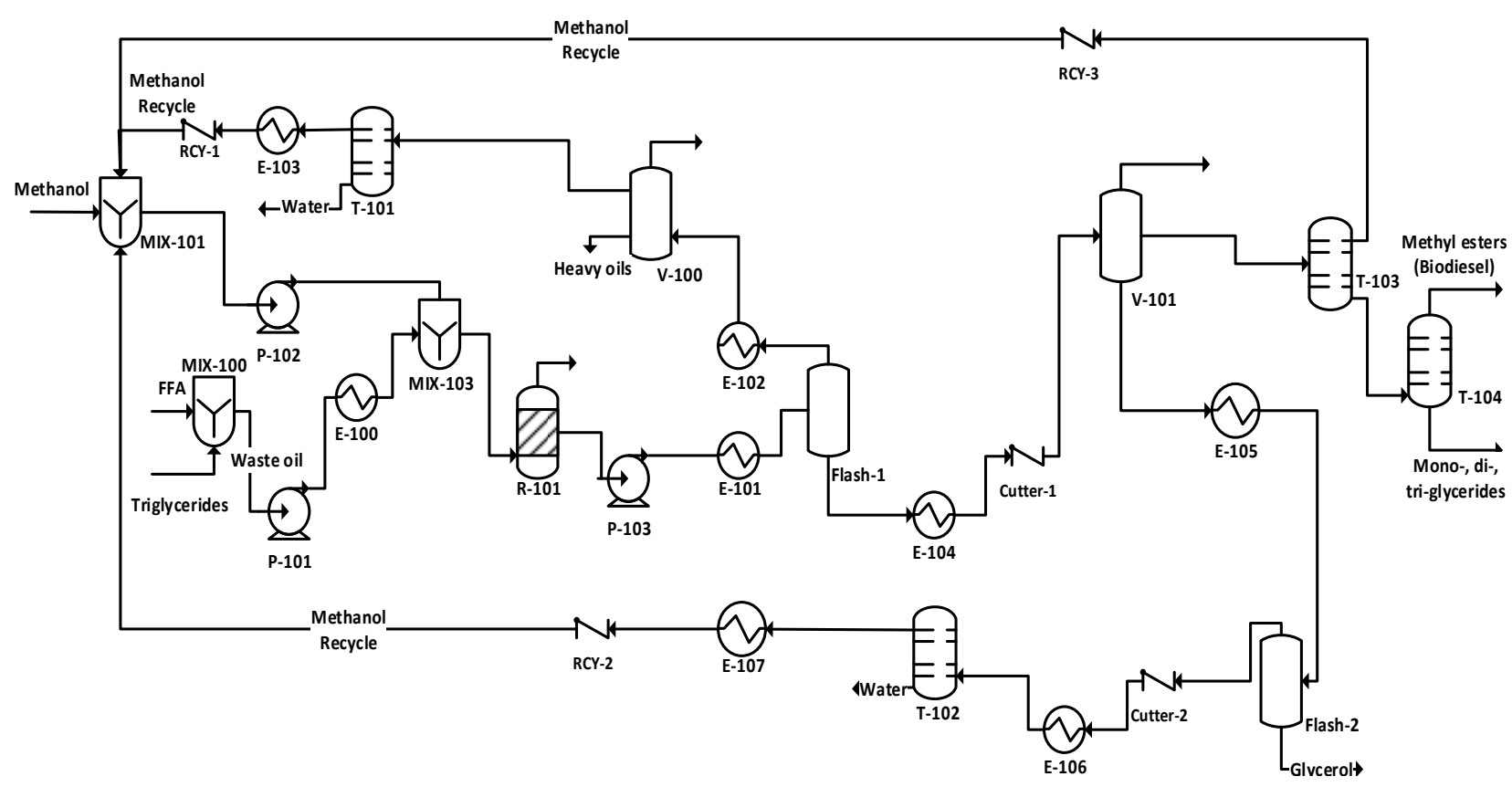




\subsubsection{Step 2.5: Analysis of Base Case Design}

The feed in the base case design contains triglycerides and free fatty acids which correspond to a waste cooking oil feedstock. Therefore, having the base case flowsheet, a more detailed rigorous simulation was now performed. Note, in course of simultaneous simulation of the superstructure, less number of compounds and reactions were considered for the sake of simplicity of the simulations. Waste cooking palm oil consists of a mixture of triglyceride (e.g., trilaurin, tripalmitin, triolein, tristearin, trilinolein and trilinolenin) and free fatty acids (e.g., lauric acid, palmitic acid, stearic acid, oleic acid, linoleic and linolenic acid). The composition of the feedstock is given in Table 7.

Table 7. Mole fraction of the compounds that form the waste cooking oil in the base case design.

\begin{tabular}{clc}
\hline & \multicolumn{1}{c}{ Compound } & Mole fraction in the feed \\
\cline { 2 - 3 } & Trilaurin & 0.0010 \\
Triglycerides & Trimyristin & 0.0087 \\
& Tripalmitin & 0.3351 \\
& Tristearin & 0.0319 \\
& Triolein & 0.2892 \\
& Trilinolein & 0.0726 \\
& Trilinolenin & 0.0029 \\
\hline \multirow{2}{*}{ Free Fatty Acids } & Lauric acid & 0.0003 \\
& Myristic acid & 0.0030 \\
& Palmitic acid & 0.1132 \\
& Stearic acid & 0.0107 \\
& Oleic acid & 0.0972 \\
& Linoleic acid & 0.0244 \\
& Linolenic acid & 0.0097 \\
\hline
\end{tabular}

The main reaction for biodiesel production consists of the three-step transesterification of triglyceride (trilaurin, tripalmitin, triolein, tristearin, trilinolein and trilinolenin), diglyceride (dilaurin, dipalmitin, diolein, distearin, dilinolein, dilinolenin) and monoglyceride (monolaurin, monopalmitin, monoolein, monolinolenin) with methanol as shown below. Note that the $\mathrm{RCOOCH}_{3}$ is the biodiesel product which is a mixture of (methyl laurate, methyl myristate, methyl palmitate, methyl stearate, methyl oleate, methyl linoleate).

$$
\begin{gathered}
\text { Triglyceride }+\mathrm{CH}_{3} \mathrm{OH} \leftrightarrow \text { Diglycerides }+\mathrm{RCOOCH}_{3} \\
\text { Diglyceride }+\mathrm{CH}_{3} \mathrm{OH} \leftrightarrow \text { Monoglyceride }+\mathrm{RCOOCH}_{3} \\
\text { Monoglyceride }+\mathrm{CH}_{3} \mathrm{OH} \leftrightarrow \text { Glycerol }+\mathrm{RCOOCH}_{3}
\end{gathered}
$$

When an esterification is applied to reduce free fatty acids in waste cooking oil, the following reaction where water is produced as a by-product, takes place:

$$
\mathrm{RCOOH}+\mathrm{CH}_{3} \mathrm{OH} \leftrightarrow \mathrm{RCOOCH}_{3}+\mathrm{H}_{2} \mathrm{O}
$$


Figure 7. Calculated mass (in $\mathrm{kg} / \mathrm{h}$ ) and energy $(\mathrm{GJ} / \mathrm{h}$ ) balance for the base case design of biodiesel production process.

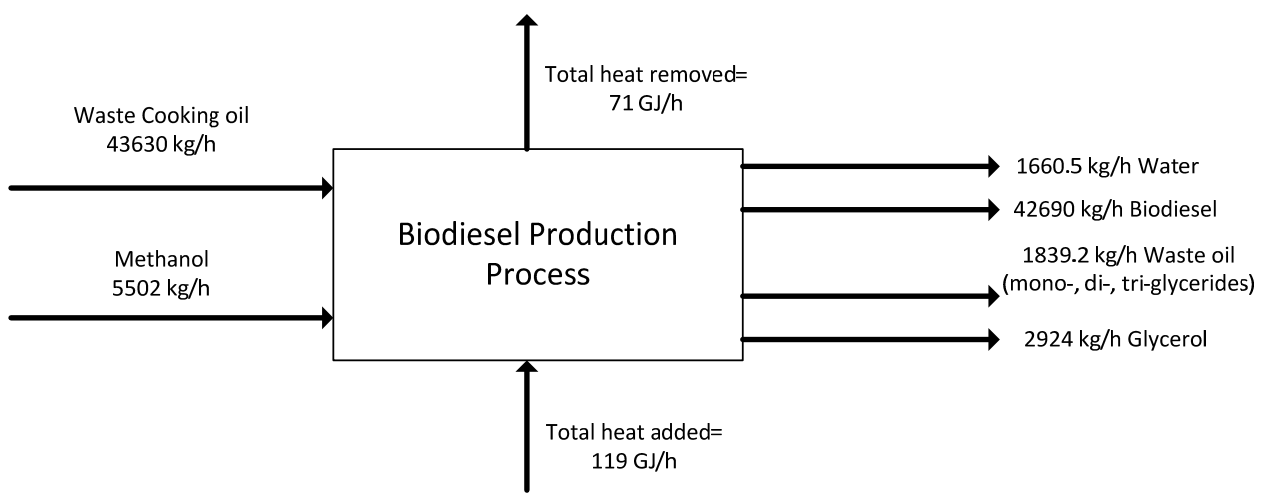

Figure 8. Presentation of closed- and open-paths that include process bottlenecks in the base design for production of biodiesel.



Simulation of biodiesel production is performed using the Aspen Hysys process simulator. All the triglycerides and free fatty acids mentioned above are defined using a "Hypo manager" tool. A waste cooking palm oil containing $10 \mathrm{wt} . \%$ of free fatty acids at the flow rate of $62.48 \mathrm{kmol} / \mathrm{h}$ is used as feedstock for detailed simulation of biodiesel production base case design that was obtained in Step 2.4. Fresh methanol was supplied at the flowrate of $171.1 \mathrm{kmol} / \mathrm{h}$. The mass and energy balance are simply depicted in Figure 7. Note that the recycle of excess methanol to the reactor is not shown on this figure. This is shown in Figure 8 and also the suggested excess amounts are listed in Table 2.

The updated sustainability indicators, metrics and LCA on the more detailed base case calculations are given in Tables 8 and 9 and the paths with which they are associated are given in Figure 8 .

Table 8. List of selected open-path indicators.

\begin{tabular}{ccccc}
\hline Path & Compound & Flowrate $(\mathbf{k g} / \mathbf{h})$ & MVA $\left._{\left(10^{3}\right.}^{\mathbf{\$}} / \mathbf{y}\right)$ & TVA $\left.^{\left(10^{3}\right.} \mathbf{\$} / \mathbf{y}\right)$ \\
\hline OP4 & Methyl oleate & 174.1 & -2047.2 & -2052.3 \\
OP5 & Methanol & 3129.8 & -14174.3 & -14898.1 \\
\hline
\end{tabular}


Table 9. List of the principal closed-path indicators (EWC and AF).

\begin{tabular}{cccccc}
\hline Path & Compound & Flowrate $(\mathbf{k g} / \mathbf{h})$ & EWC $\left(\mathbf{1 0}^{\mathbf{3}} \mathbf{\$} / \mathbf{y}\right)$ & $\mathbf{A F}\left(\mathbf{1 0}^{\mathbf{3}} \mathbf{\$} / \mathbf{y}\right)$ & Score * \\
\hline CP2 & Methanol & 1402.6 & 496.7 & 0.246 & High \\
\hline \multicolumn{5}{c}{ * a high score indicates a high potential for change. }
\end{tabular}

It can be seen in the Table 8, that methanol has a very negative value in terms of MVA and TVA indicators; therefore, this indicates very high raw material loss and energy consumption in the OP4. The same also applies to methyl oleate in this path.

From Table 9, it can be observed that methanol has very high EWC value in a closed-path, which refers to a recycle stream. Thus, this path is identified as the one that contains the unit operations with potential bottlenecks. Table 10 gives a selected list of the sustainability metrics for the base case design.

Table 10. Sustainability metrics for the base case design.

\begin{tabular}{ccccc}
\hline $\begin{array}{c}\text { MJ energy/kg } \\
\text { product }\end{array}$ & $\begin{array}{c}\text { kg product/kg raw } \\
\text { material }\end{array}$ & kg waste/kg product & $\begin{array}{c}\text { Total kg CO} \\
\text { Equivalent }\end{array}$ & $\begin{array}{c}\text { Total utility costs } \\
\text { (\$)/year }\end{array}$ \\
\hline 2.5 & 0.94 & 0.034 & 0.183 & $7,790,000$ \\
\hline
\end{tabular}

The economic and life cycle assessment analysis were also updated for the more detailed base case calculations and these are highlighted in Figures 9 and 10. From Figure 9 it can be seen that the reboilers of columns rT-103, rT-101 and rT-104 and heat exchanger E-101 have the largest utility costs in the process and therefore these are stored as process bottlenecks (high energy consumption) with respect to utility costs. This is not surprising, however, the analysis also points out the operation with the largest utility cost. From Figure 10, it can be seen that the same heat exchanger (E-101), reboilers of the same columns rT-103, rT-104 and rT-101, and the reactor (R-101) have the largest carbon footprint for biodiesel production because of their high utility (energy) consumption.

The characteristics of the unit operations, for example, the above energy consumption analysis were stored as the final set of process bottlenecks. This information is useful because if these process bottlenecks are improved/eliminated then the new process alternative will be more sustainable and offer more economic benefits. Note that removing these bottlenecks means improvements in the corresponding indicators (from sustainability analysis), which in turns means improvement in the sustainability metrics. Thereby, a more sustainable process design is obtained. A list of the equipment according to their identification as a major bottleneck in the three (sustainability, cost, LCA) analyses is given in Table 11. It can be seen that columns T-101, T-102, heat exchanger (E-101) and reactor (R-101) have appeared as a bottleneck in all three analyses. Therefore, from this analysis it can be concluded that the major bottleneck of the process is very high energy consumption, which can be overcome by reducing the utility consumption and consequently utility costs. 
Figure 9. Percentage of the total utility costs with respect to each activity/unit operation.

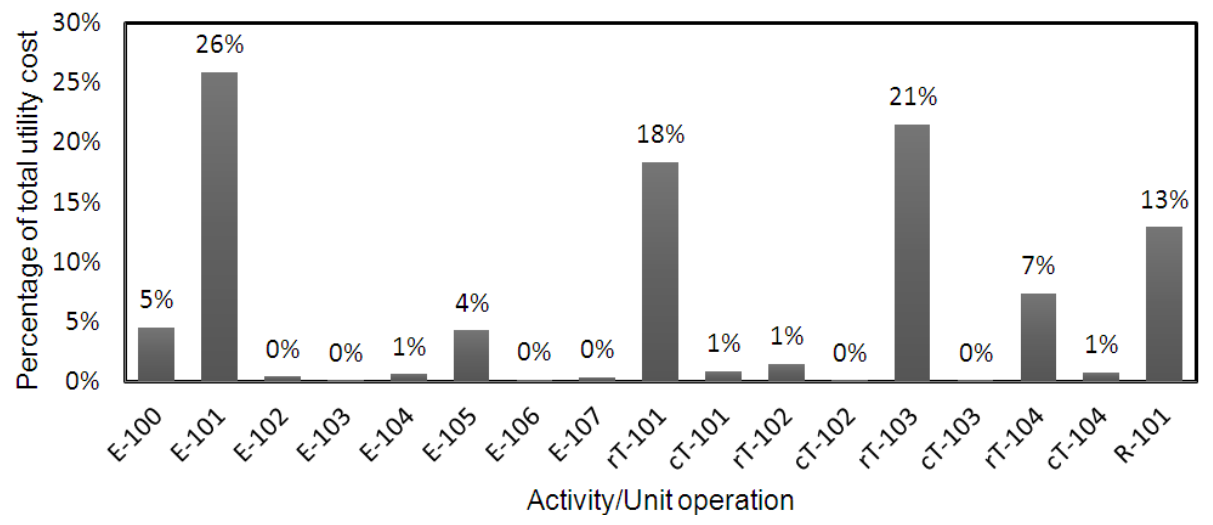

Figure 10. Carbon footprint of different activities/unit operations in the base case design for biodiesel production.

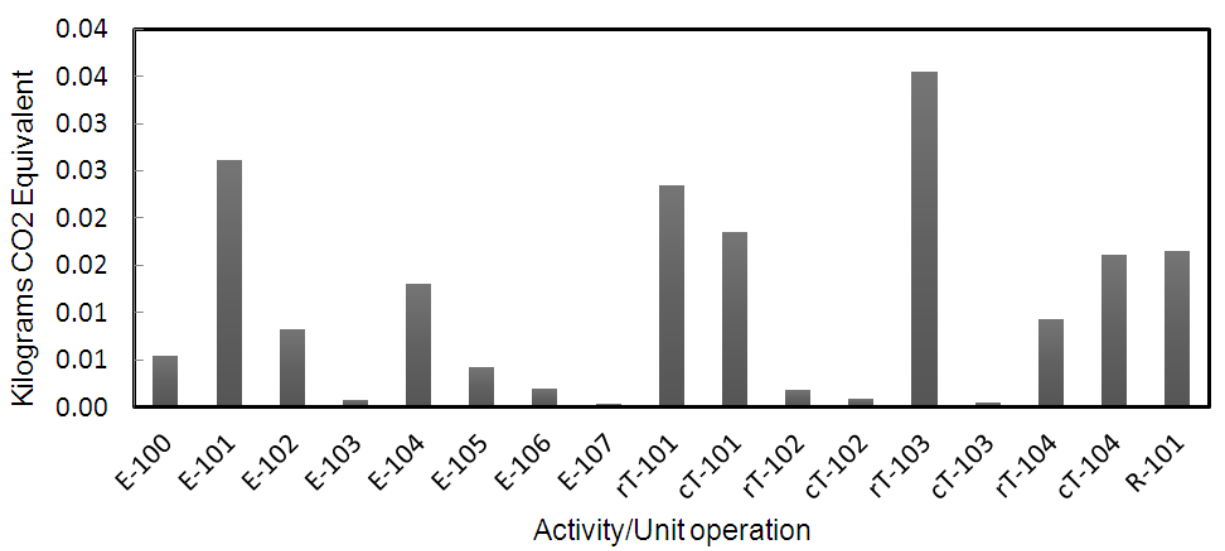

Table 11. Main identified bottlenecks with respect to sustainability, economic and life cycle assessment (LCA) analysis.

\begin{tabular}{lcccc}
\hline \multicolumn{1}{c}{ Unit } & Label & Sustainability & LCA & Economic \\
\hline Reactor & R-101 & $\mathrm{x}$ & $\mathrm{x}$ & $\mathrm{x}$ \\
Column & $\mathrm{T}-101$ & $\mathrm{x}$ & & $\mathrm{x}$ \\
Column & $\mathrm{T}-102$ & $\mathrm{x}$ & $\mathrm{x}$ & \\
Column & $\mathrm{T}-103$ & $\mathrm{x}$ & $\mathrm{x}$ & $\mathrm{x}$ \\
Column & $\mathrm{T}-104$ & $\mathrm{x}$ & $\mathrm{x}$ & $\mathrm{x}$ \\
Heat exchanger & $\mathrm{E}-100$ & $\mathrm{x}$ & & $\mathrm{x}$ \\
Heat exchanger & $\mathrm{E}-101$ & & $\mathrm{x}$ & $\mathrm{x}$ \\
\hline
\end{tabular}

\subsection{Part-3: Sustainable Design Options}

\subsubsection{Step 3.1: Problem and Objective Function Definition}

The PI problem is defined as follows: to achieve and identify an intensified process flowsheet for the production of biodiesel and glycerol with maximum purity and conversion of raw materials that is $>97 \%$ vegetable/waste oil while reducing the operating costs of the process. 
Table 12. Performance metrics and their associated constraints at logical (L), Structural (S), Operational (O) and PI screening (PIs) levels.

\begin{tabular}{|c|c|c|c|c|c|}
\hline Performance metric & $\mathbf{L}$ & $\mathbf{S}$ & $\mathbf{O}$ & $\mathbf{P I}_{\mathrm{s}}$ & Constraint description \\
\hline \multirow{3}{*}{ Reactor } & $\mathrm{x}$ & & & & Reaction is present \\
\hline & $\mathrm{x}$ & & & & Reaction is inside the first unit operation \\
\hline & $\mathrm{x}$ & & & & $\begin{array}{l}\text { The reactor effluent is connected to a separation sequence according to } \\
\text { the product purity defined in the base case design }\end{array}$ \\
\hline Capital Costs & & $\mathrm{x}$ & & & $\begin{array}{l}\text { Identify possible units and allow only a number of units (defined in step } \\
1 \text { or by screening) }\end{array}$ \\
\hline \multirow{4}{*}{ Efficiency } & & $\mathrm{x}$ & & & Do not integrate phenomena which inhibit each other's performance \\
\hline & & & & $\mathrm{x}$ & Product-yield \\
\hline & & & & $\mathrm{x}$ & Higher separation efficiency \\
\hline & & $\mathrm{x}$ & & & $\begin{array}{l}\text { Do not connect phenomena in a series of co-current stages with } \\
\text { decreasing efficiency/equilibrium }\end{array}$ \\
\hline \multirow{2}{*}{ Energy } & & $\mathrm{x}$ & & & $\begin{array}{l}\text { Do not connect phenomena to a series with alternating heat addition and } \\
\text { heat removal }\end{array}$ \\
\hline & & $\mathrm{x}$ & & & $\begin{array}{l}\text { Remove options in which phenomena are heated/cooled leading to a } \\
\text { decrease of the efficiency }\end{array}$ \\
\hline \multirow{2}{*}{ Operational Costs } & & & $\mathrm{x}$ & & Utility costs \\
\hline & & & & $\mathrm{x}$ & Utility costs \\
\hline \multirow[b]{2}{*}{ Simplification } & & $\mathrm{x}$ & & & Remove options with redundant stages \\
\hline & & $\mathrm{x}$ & & & $\begin{array}{l}\text { Identify possible units and allow only a number of units (defined in step } \\
1 \text { or by screening) }\end{array}$ \\
\hline Waste minimization & & $\mathrm{x}$ & & & $\begin{array}{l}\text { Ensure that phenomena are connected so that the best use of or recycle } \\
\text { of raw materials is achieved }\end{array}$ \\
\hline \multirow{2}{*}{ Raw materials } & & & $\mathrm{x}$ & & Raw materials are pure \\
\hline & & & $\mathrm{x}$ & & Yield $\geq 97 \%$ \\
\hline Equipment & & & & $\mathrm{x}$ & PI screening equipment: Novel equipment \\
\hline
\end{tabular}

The objective function is shown in Equation (9) where $c_{i}$ represents the cost of raw materials and $c_{j}$ the cost of energy, $\dot{m}_{i}$ represents the mass flowrate of the raw materials, $\dot{m}_{k}$ represents the mass flowrate of products and $\dot{e}$ represents the utility usage. Note that subscripts $i, j, k$ represent raw material, energy and products, respectively. It should be mentioned that as a result of intensification the number and/or volume of unit operations may decrease which will consequently result in a reduction of capital costs.

$$
\min F_{o b j}=\left(\frac{\sum c_{i} \dot{m}_{i}+\sum c_{j} \dot{e}}{\sum \dot{m}_{k}}\right)
$$

The performance metrics were selected and categorized in terms of logical (L), structural (S), operational $(\mathrm{O})$ and PI screening constraints and are given in Table 12. The product specifications are defined to be the same as the base case design.

\subsubsection{Step 3.2: Analyze the Process}

In this step the mass and energy balance steady state data were collected from the rigorous simulation of the more detailed simulated base case design. The base case design flowsheet was then transformed into a task based flowsheet, which identifies different tasks in the process in terms of 
mixing, reaction and/or separation tasks. This task based flowsheet was then transformed into a phenomena based flowsheet using a PI knowledge base. The task-based and phenomena-based flowsheets are shown in Figures 11 and 12, respectively.

Using the task and phenomena based flowsheets of the base case design; the previously identified process bottlenecks of the base case design are linked to the phenomena and the tasks inside and outside of the unit operation in which they occur. To further analyze the system to identify the bottlenecks, the needed pure compound properties are retrieved from ICAS database [24] for computing the binary ratio matrix of properties. Excerpts of these results are given in Tables 13 (for pure compound properties) and 14 (for binary ratio matrix).

Figure 11. Task-based flowsheet of the base case design for biodiesel production process.

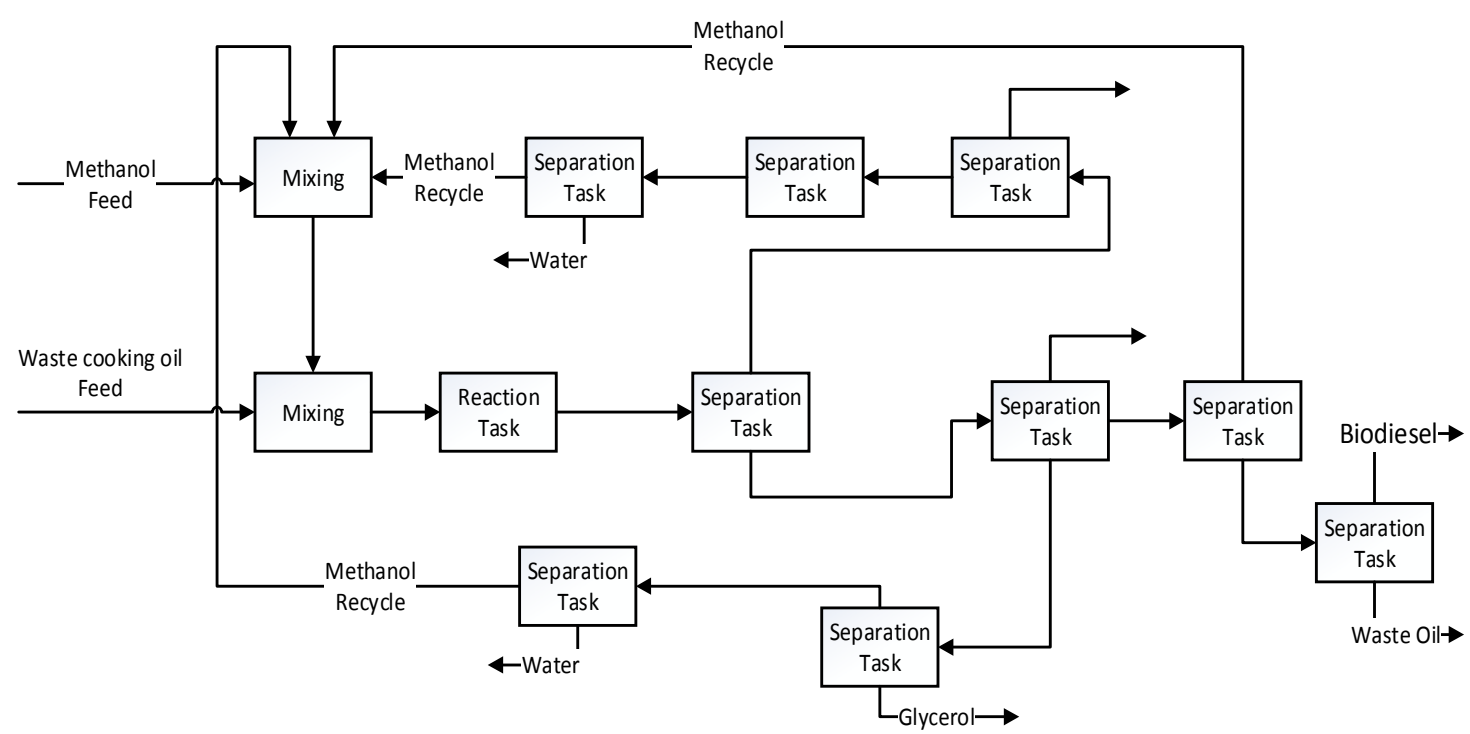

Figure 12. Phenomena-based flowsheet of the biodiesel production process according to the existing phenomena in the base case design.

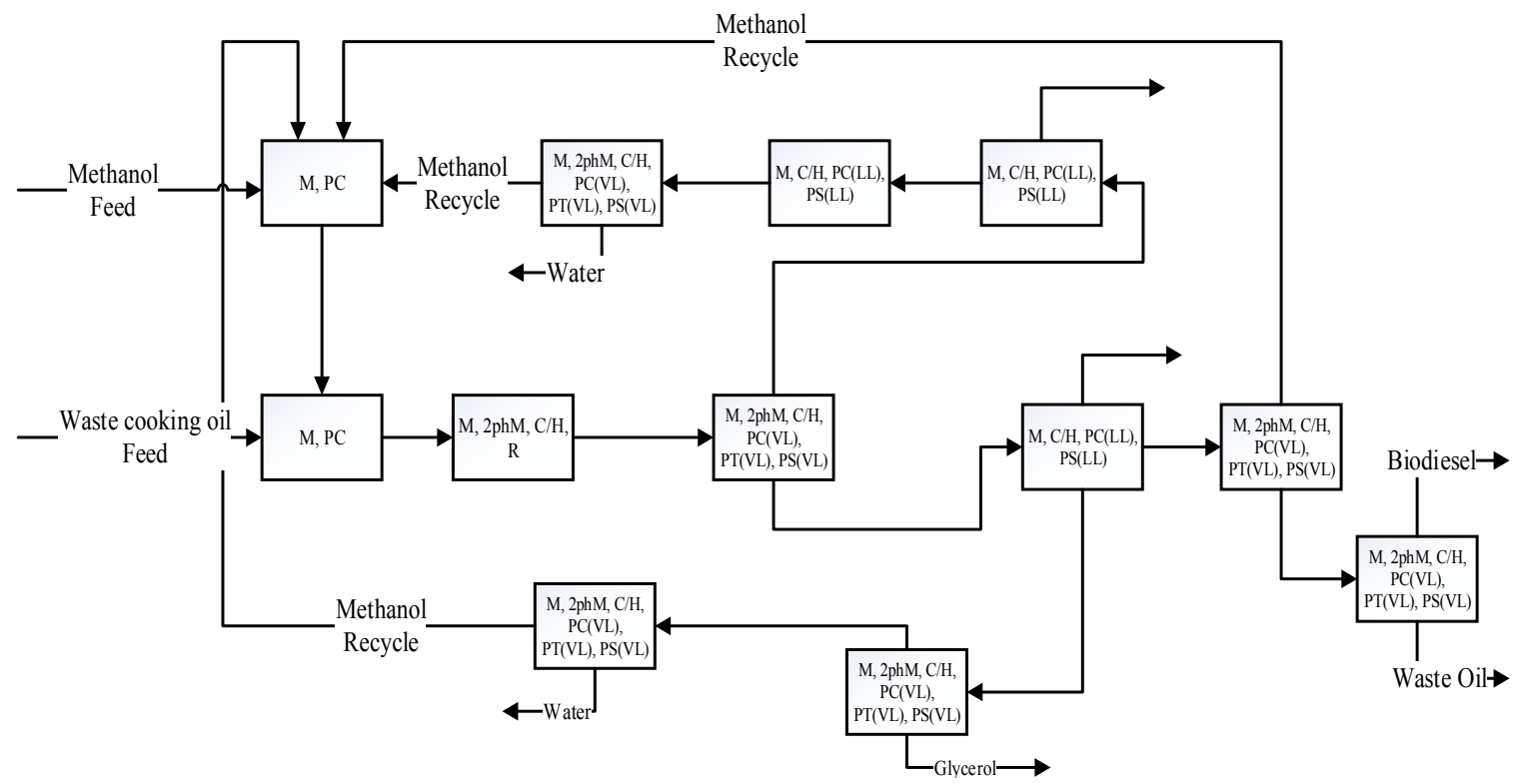


Table 13. List of the pure compound properties of some of the compounds in the system.

\begin{tabular}{|c|c|c|c|c|c|c|c|c|c|}
\hline Compound & MW (g/mol) & $\mathbf{T}_{\mathrm{c}}(\mathbf{K})$ & $\mathbf{P}_{\mathrm{c}}$ (bar) & $\mathbf{T}_{\mathbf{b}}(\mathbf{K})$ & $\mathbf{T}_{\mathrm{m}}(\mathbf{K})$ & $\begin{array}{l}\text { Solubility } \\
\text { parameter } \\
\left(\mathbf{M P a}^{\wedge} \mathbf{0 . 5}\right)\end{array}$ & $\begin{array}{c}\text { Radius of gyration } \\
\text { (§̊) }\end{array}$ & $\mathbf{V}_{\mathbf{V d W}}$ & $\mathbf{V}_{\mathbf{m}}$ \\
\hline Methanol & 32.0 & 512.4 & 72.8 & 337.6 & 175.3 & 29.61 & 1.5520 & 0.0217 & $4.08 \times 10^{-2}$ \\
\hline Water & 18.0 & 747.1 & 218.4 & 373.0 & 273.0 & 47.79 & 0.6150 & 0.0123 & $1.79 \times 10^{-2}$ \\
\hline Glycerol & 92.0 & 724.8 & 65.8 & 561.8 & 291.2 & 34.99 & 3.5199 & 0.0513 & $7.13 \times 10^{-2}$ \\
\hline Lauric acid & 200.3 & 733.8 & 19.05 & 571.7 & 342.31 & 19.96 & 6.6009 & 0.13549 & 0.2262 \\
\hline Methyl laurate & 214.3 & 711.8 & 19.9 & 539.2 & 278.1 & 19.74 & 18.6656 & 0.1448 & 0.2067 \\
\hline Monolaurin & 274.4 & 857.4 & 17.3 & 625.6 & 351.3 & 18.81 & 7.0445 & - & 0.3076 \\
\hline Dilaurin & 456.7 & 916.7 & 11.2 & 703.1 & 372.5 & 14.61 & 8.8250 & - & 0.5109 \\
\hline Trilaurin & 639.0 & 998.7 & 9.5 & 767.2 & 386.8 & 13.97 & 9.6796 & - & 0.7151 \\
\hline
\end{tabular}

Table 14. Computed binary ratio matrix for some of the compounds of the system.

\begin{tabular}{|c|c|c|c|c|c|c|c|c|c|c|}
\hline \multirow{2}{*}{$\begin{array}{l}\text { Ratio of properties of } \\
\text { binary pairs }\end{array}$} & \multicolumn{10}{|c|}{ Property ratio } \\
\hline & MW & $\begin{array}{c}\text { Critical } \\
\text { temperature }\left(T_{c}\right) \\
\end{array}$ & $\begin{array}{c}\text { Critical } \\
\text { pressure }\left(\boldsymbol{P}_{c}\right) \\
\end{array}$ & $\begin{array}{c}\text { Boiling } \\
\text { temperature }\left(T_{b}\right) \\
\end{array}$ & $\begin{array}{c}\text { Melting } \\
\text { temperature }\left(T_{m}\right)\end{array}$ & $\begin{array}{l}\text { Solubility } \\
\text { parameter }\end{array}$ & Radius of gyration & $\mathbf{V}_{\mathrm{VdW}}$ & $\mathbf{V}_{\mathbf{m}}$ & $\begin{array}{c}\text { Binary azeotrope } \\
\text { at } P=1 \mathrm{~atm}\end{array}$ \\
\hline Methnol/Water & 1.78 & 1.44 & 3.03 & 1.67 & 1.56 & 1.61 & 2.52 & 1.76 & 2.28 & No \\
\hline Methanol/Glycerol & 2.85 & 1.41 & 1.11 & 1.59 & 1.67 & 1.17 & 2.27 & 2.38 & 1.75 & No \\
\hline Methanol/Methyl laurate & 6.66 & 1.39 & 3.64 & 1.85 & 1.59 & 1.50 & 12.50 & 6.67 & 5.00 & No \\
\hline Methanol/Lauric aicd & 6.25 & 1.43 & 3.82 & 2.08 & 1.96 & 1.48 & 4.17 & 6.25 & 5.56 & No \\
\hline Methanol/Monolaurin & 8.33 & 1.67 & 4.21 & 2.27 & 2.00 & 1.57 & 4.55 & 0.00 & 7.69 & No \\
\hline Methanol/Dilaurin & 14.29 & 1.79 & 6.50 & 1.04 & 2.13 & 2.03 & 5.56 & 0.00 & 12.50 & No \\
\hline Methanol/Trilaurin & 20.00 & 1.96 & 7.68 & 1.11 & 2.22 & 2.12 & 6.25 & 0.00 & 16.67 & No \\
\hline Water/Glycerol & 5.00 & 1.03 & 3.32 & 1.25 & 1.06 & 1.37 & 5.88 & 4.17 & 4.00 & No \\
\hline Water/Methyl laurate & 12.50 & 1.05 & 10.92 & 1.37 & 1.02 & 2.42 & 33.33 & 11.11 & 11.11 & No \\
\hline Water/Lauric acid & 11.11 & 1.02 & 11.46 & 1.16 & 1.25 & 2.39 & 11.11 & 11.11 & 12.50 & No \\
\hline Water/Monolaurin & 14.29 & 1.14 & 12.63 & 1.10 & 1.28 & 2.54 & 11.11 & 0.00 & 16.67 & No \\
\hline Water/Dilaurin & 25.00 & 1.21 & 19.48 & 1.52 & 1.37 & 3.27 & 14.29 & 0.00 & 33.33 & No \\
\hline
\end{tabular}


Table 14. Cont.

\begin{tabular}{|c|c|c|c|c|c|c|c|c|c|c|}
\hline \multirow{2}{*}{$\begin{array}{l}\text { Ratio of properties of } \\
\text { binary pairs }\end{array}$} & \multicolumn{10}{|c|}{ Property ratio } \\
\hline & MW & $\begin{array}{c}\text { Critical } \\
\text { temperature }\left(T_{c}\right)\end{array}$ & $\begin{array}{c}\text { Critical } \\
\text { pressure }\left(\boldsymbol{P}_{c}\right)\end{array}$ & $\begin{array}{c}\text { Boiling } \\
\text { temperature }\left(T_{b}\right)\end{array}$ & $\begin{array}{c}\text { Melting } \\
\text { temperature }\left(T_{m}\right)\end{array}$ & $\begin{array}{l}\text { Solubility } \\
\text { parameter }\end{array}$ & Radius of gyration & $\mathbf{V}_{\mathrm{VdW}}$ & $\mathbf{V}_{\mathrm{m}}$ & $\begin{array}{c}\text { Binary azeotrope } \\
\text { at } P=1 \mathrm{~atm}\end{array}$ \\
\hline Water/Trilaurin & 33.33 & 1.33 & 23.03 & 1.30 & 1.41 & 3.42 & 16.67 & 0.00 & 33.33 & No \\
\hline Glycerol/Methyl laurate & 2.33 & 1.02 & 3.29 & 1.43 & 1.05 & 1.77 & 5.26 & 2.86 & 2.94 & No \\
\hline Glycerol/Lauric acid & 2.17 & 1.01 & 3.45 & 1.12 & 1.18 & 1.75 & 1.89 & 2.63 & 3.13 & No \\
\hline Glycerol/Monolaurin & 2.94 & 1.18 & 3.81 & 1.22 & 1.20 & 1.86 & 2.00 & 0.00 & 4.35 & No \\
\hline Glycerol/Dilaurin & 5.00 & 1.27 & 5.87 & 1.09 & 1.28 & 2.40 & 2.50 & 0.00 & 7.14 & No \\
\hline Glycerol/Trilaurin & 7.14 & 1.37 & 6.94 & 1.67 & 1.33 & 2.51 & 2.78 & 0.00 & 10.00 & No \\
\hline Methyl laurate/Lauric acid & 1.07 & 1.03 & 1.05 & 1.59 & 1.23 & 1.01 & 2.83 & 1.07 & 1.10 & No \\
\hline Methyl laurate/Monolaurin & 1.28 & 1.20 & 1.16 & 1.85 & 1.27 & 1.05 & 2.65 & 0.00 & 1.49 & No \\
\hline Methyl laurate/Dilaurin & 2.13 & 1.28 & 1.78 & 2.08 & 1.33 & 1.35 & 2.12 & 0.00 & 2.50 & No \\
\hline Methyl laurate/Trilaurin & 2.94 & 1.41 & 2.11 & 2.27 & 1.39 & 1.41 & 1.93 & 0.00 & 3.45 & No \\
\hline Lauric acid/Monolaurin & 1.37 & 1.16 & 1.10 & 1.04 & 1.03 & 1.06 & 1.06 & 0.00 & 1.35 & No \\
\hline Lauric acid/Dilaurin & 2.27 & 1.25 & 1.70 & 1.11 & 1.09 & 1.37 & 1.33 & 0.00 & 2.27 & No \\
\hline Lauric acid/Trilaurin & 3.23 & 1.37 & 2.01 & 1.25 & 1.14 & 1.43 & 1.47 & 0.00 & 3.13 & No \\
\hline Monolaurin/Dilaurin & 1.67 & 1.06 & 1.54 & 1.37 & 1.06 & 1.29 & 1.25 & 0.00 & 1.67 & No \\
\hline Monolaurin/Trilaurin & 2.33 & 1.16 & 1.82 & 1.16 & 1.10 & 1.35 & 1.37 & 0.00 & 2.33 & No \\
\hline Dilaurin/Trilaurin & 1.41 & 1.09 & 1.18 & 1.10 & 1.04 & 1.05 & 1.10 & 0.00 & 1.41 & No \\
\hline
\end{tabular}

Table 15. Decisions for finding the desirable task for overcoming the process bottlenecks caused by primary task.

\begin{tabular}{|c|c|c|c|c|c|c|c|}
\hline \multirow{2}{*}{ Bottleneck } & \multicolumn{2}{|c|}{ Primary task } & \multicolumn{5}{|c|}{ Desirable task } \\
\hline & Reaction & Separation & Reaction & Separation & Mixing & Cooling & Heating \\
\hline Activation problem & $\mathrm{x}$ & & $\mathrm{x}$ & & $\mathrm{x}$ & & $\mathrm{x}$ \\
\hline Contact problems of raw materials/limited mass transfer & $\mathrm{x}$ & $\mathrm{x}$ & & & $\mathrm{x}$ & & \\
\hline Formation of undesirable side products & $\mathrm{x}$ & $\mathrm{x}$ & $\mathrm{x}$ & $\mathrm{x}$ & & & \\
\hline High energy consumption/demand & $\mathrm{x}$ & $\mathrm{x}$ & $\mathrm{x}$ & $\mathrm{x}$ & & & \\
\hline Highly endothermic reaction & $\mathrm{x}$ & & & & & $\mathrm{x}$ & $\mathrm{x}$ \\
\hline Limiting equilibrium & $\mathrm{x}$ & & $\mathrm{x}$ & $\mathrm{x}$ & $\mathrm{x}$ & & \\
\hline Difficult separation due to low driving force & & $\mathrm{x}$ & $\mathrm{x}$ & $\mathrm{x}$ & & & \\
\hline
\end{tabular}


Besides the previously identified process bottlenecks, that is, high energy consumption (identified in Step 2.5), presence of limited equilibrium reaction is also identified as a further process bottleneck (see Table 15).

\subsubsection{Step 3.3: Identification of Desirable Phenomena}

In this step desirable tasks which are then translated into phenomena are identified for overcoming all the identified process bottlenecks. The identified desirable tasks are listed in Table 15.

In order to identify the feasible phenomena to overcome these bottlenecks, the tasks given in Table 15 need to be translated into phenomena using thermodynamic insights and the operating window of each phenomenon. The identified phenomena to overcome the bottlenecks are given in Table 16.

Table 16. Translation of the desirable tasks into phenomena.

\begin{tabular}{|c|c|c|c|c|c|}
\hline Task & $\begin{array}{c}\text { Feed } \\
\text { condition }\end{array}$ & Separation type & Phenomena & Pure compound property & $\begin{array}{c}\text { Solvent } \\
\text { required? }\end{array}$ \\
\hline $\begin{array}{l}\text { Absorption } \\
\text { separation }\end{array}$ & $\mathrm{V}$ & Gas-separation & $\mathrm{PT}(\mathrm{VL})$ & Solubility parameter & Yes \\
\hline $\begin{array}{l}\text { Supercritical } \\
\text { extraction }\end{array}$ & $\mathrm{L} / \mathrm{V}$ & VL & $\mathrm{PT}(\mathrm{VL})$ & $\begin{array}{l}\text { Solubility parameter, critical } \\
\text { pressure }\end{array}$ & Yes \\
\hline $\begin{array}{l}\text { V-L separation based } \\
\text { on boiling points }\end{array}$ & $\mathrm{V} / \mathrm{VL} / \mathrm{L}$ & VL & PT(VL) & $\begin{array}{l}\text { Vapor pressure } * \text {, heat of } \\
\text { vaporization } * \text {, boiling point, } \\
\text { solubility parameter }\end{array}$ & No \\
\hline $\begin{array}{l}\text { Vapor permeation } \\
\text { separation }\end{array}$ & $\mathrm{L}$ & Vapor-separation & PT(P:VV) & $\begin{array}{l}\text { Molar volume, solubility parameter, } \\
\text { dipole moment }\end{array}$ & No \\
\hline $\begin{array}{l}\text { Pervaporation } \\
\text { separation }\end{array}$ & V & Vapor-separation & $\mathrm{PT}(\mathrm{P}: \mathrm{VL}) * *$ & $\begin{array}{l}\text { Molar volume, solubility parameter, } \\
\text { dipole moment * }\end{array}$ & No \\
\hline Stripping separation & $\mathrm{V} / \mathrm{VL} / \mathrm{L}$ & VL & $\mathrm{PT}(\mathrm{VL})$ & Solubility parameter & Yes \\
\hline $\begin{array}{l}\text { Separation by Boiling } \\
\text { points }\end{array}$ & $\mathrm{V} / \mathrm{VL} / \mathrm{L}$ & VL & $\mathrm{PT}(\mathrm{VL})$ & $\begin{array}{l}\text { Vapor pressure } * \text {, heat of } \\
\text { vaporization *, boiling point }\end{array}$ & No \\
\hline
\end{tabular}

* The parameter was not considered in calculating binary ratio matrix; **(P:) denotes permeation.

All accompanying phenomena are selected by consulting the knowledge base tool for each identified phenomena. In total 15 phenomena building blocks are identified: mixing; ideal $\left(\mathrm{M}_{\mathrm{id}}\right)$, tubular flow $\left(\mathrm{M}_{\mathrm{tub}}\right)$, rectangular flow $\left(\mathrm{M}_{\mathrm{rec}}\right)$, 2-phase mixing $(2 \mathrm{phM})$ : ideal; dividing $(\mathrm{D})$; heating $(\mathrm{H})$ and cooling (C); reaction (R); phase contact V-L, V-V (PC); phase transition V-L, P:VV, P:VL (PT); phase separation V-L, V-V (PS).

\subsubsection{Step 3.4: Generate Feasible Operation/Flowsheet Options}

In this step the phenomena building blocks are connected to form SPBs, for example, phenomena for mixing, reaction and heating can be combined to form an SPB if the reaction is endothermic, that is, $\mathrm{M}=\mathrm{R}=\mathrm{H}$. The total number of SPBs that can be generated from the 15 identified phenomena building blocks are calculated using Equations (10) and (11) [13] and is found to be 16,278. In Equation (10), $\mathrm{n}_{\mathrm{Ph}, \max }$ is the maximum number of phenomena that can be present in an $\mathrm{SPB}, \mathrm{Ph}_{\mathrm{BB}}$ is the 
total number of phenomena building blocks, $15, \mathrm{Ph}_{\mathrm{E}}$ is the total number of energy transfer phenomena, 2, $\mathrm{Ph}_{\mathrm{M}}$ is the total number of mixing phenomena and $\mathrm{Ph}_{\mathrm{D}}$ is the dividing phenomena, 1. In Equation (11) $\mathrm{NSPB}_{\text {max }}$ is the total number of possible SPBs,

$$
\begin{aligned}
& n_{P h, \text { Max }}=P h_{B B}-\left(P h_{E}-1\right)-\left(P h_{M}-1\right)-P h_{D}=11 \\
& N S P B_{\text {Max }}=\sum_{k=1}^{n_{P h, \text { max }}}\left[\frac{\left(P h_{B B}-1\right) !}{\left(P h_{B B}-k-1\right) ! k !}\right]+1=16278
\end{aligned}
$$

Using connectivity rules, for example, heating and cooling cannot exist in the same SPB (see SPB 5 and 6 in Table 17) or simultaneous reaction and separation can exist in the same SPB (see SPB 16 and 18 in Table 17); and the information regarding the operating window of each phenomenon, a total number of 73 SPBs were found to be feasible. Considering the three different types of mixing that is $\mathrm{M}_{\mathrm{id}}, \mathrm{M}_{\text {tub }}$ and $\mathrm{M}_{\mathrm{rec}}$, the total number of SPBs are $24 \times 3+1=73$, including dividing (D) as a separate phenomenon. An example of feasible SPBs is given in Table 17. In this table, mixing (M), 2-phase mixing $(2 \mathrm{phM})$, dividing $(\mathrm{D})$; heating $(\mathrm{H})$ and cooling $(\mathrm{C})$; reaction $(\mathrm{R})$; phase contact $\mathrm{V}-\mathrm{L}, \mathrm{V}-\mathrm{V}(\mathrm{PC})$; phase transition V-L, P:VV (V-V permeation), P:VL (V-L permeation) (PT); phase separation V-L, $\mathrm{V}-\mathrm{V}$ (PS); are connected as the phenomena in order to form the SPBs.

The SPB's were then connected to form an operation (which is a collection of SPBs) and these operations are then translated into unit operations which make up the flowsheet alternatives. An example of the generation of a flowsheet alternative is presented below.

In order to produce the products, a change of raw materials state must occur and in order to achieve this, the following task is identified: Reaction task. For overcoming the bottleneck caused by the limiting equilibrium, a task for the recovery and recycle of the unreacted raw materials to the reaction task would shift the equilibrium toward the product side. Therefore, the task identified is: Use of a recycle task. This is shown in Figure 13.

The effluent from the reactor consists of the reactants and products which must be separated. Using the binary ratio matrix (see Table 14) which is based on the pure compound properties (see Table 13) the values for ratios of the boiling points for Methanol/Glycerol, Water/Methanol, Methanol/Methyl-laurate, Methanol/Mono-, Di-, and Tri-laurin are 1.67, 1.10, 1.59, 1.85, 2.08 and 2.27 respectively, which makes separation by VL very feasible for separation of methanol and water from glycerol, methyl esters, mono-, di- and tri-glycerides [17]. Hence, two of the main involved phenomena are PT(VL)-phase transfer involving vapor-liquid and PS(VL)-phase separation involving vapor-liquid. Therefore the following task is identified for the recovery of methanol: Separation task. The task and phenomena based flowsheets are shown Figure 14.

Figure 13. Task for product production.

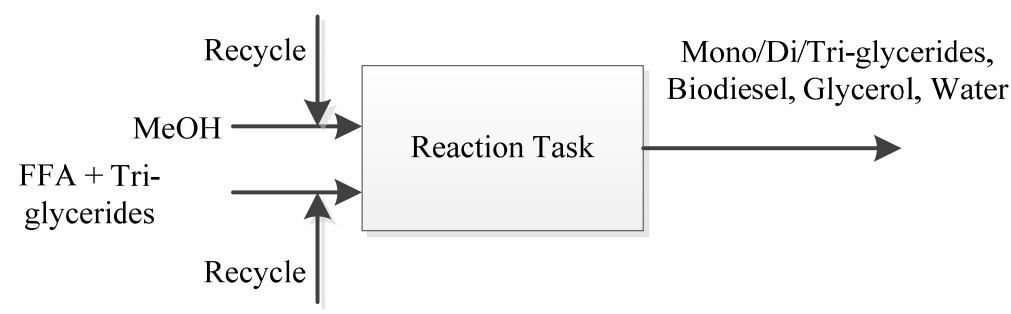


Figure 14. Task and phenomena based flowsheets for generation intensified operation.


Table 17. The identified feasible SPBs, interconnection phenomena, inlet and outlet conditions of an SPB.

\begin{tabular}{|c|c|c|c|}
\hline SPB & Interconnection Phenomena & In & Out \\
\hline 1 & M & 1..n(L) & $1(\mathrm{~L})$ \\
\hline 2 & $\mathrm{M}=\mathrm{R}$ & 1..n(L) & $1(\mathrm{~L})$ \\
\hline 3 & $\mathrm{M}=\mathrm{H}$ & 1..n(L) & $1(\mathrm{~L})$ \\
\hline 4 & $\mathrm{M}=\mathrm{C}$ & 1...n(L) & $1(\mathrm{~L})$ \\
\hline 5 & $M=R=H$ & 1..n(L) & $1(\mathrm{~L})$ \\
\hline 6 & $\mathrm{M}=\mathrm{R}=\mathrm{C}$ & 1..n(L) & $1(\mathrm{~L})$ \\
\hline 7 & $\mathrm{M}=2 \mathrm{phM}=\mathrm{PC}(\mathrm{VL})=\mathrm{PT}(\mathrm{VL})$ & 1..n(L,VL) & $1(\mathrm{~V} / \mathrm{L})$ \\
\hline 8 & $\mathrm{M}=\mathrm{R}=2 \mathrm{phM}=\mathrm{PC}(\mathrm{VL})=\mathrm{PT}(\mathrm{VL})$ & 1..n $(\mathrm{L}, \mathrm{VL})$ & $1(\mathrm{~V} / \mathrm{L})$ \\
\hline 9 & $\mathrm{M}=\mathrm{R}=2 \mathrm{phM}=\mathrm{PC}(\mathrm{VL})=\mathrm{PT}(\mathrm{P}: \mathrm{VL})$ & $1 . . \mathrm{n}(\mathrm{L}, \mathrm{VL})$ & $1(\mathrm{~V} / \mathrm{L})$ \\
\hline 10 & $\mathrm{M}=\mathrm{R}=2 \mathrm{phM}=\mathrm{PC}(\mathrm{VL})=\mathrm{PT}(\mathrm{P}: \mathrm{VL})=\mathrm{PS}(\mathrm{VL})$ & 1..n $(\mathrm{L}, \mathrm{VL})$ & $2(\mathrm{~V} ; \mathrm{L})$ \\
\hline 11 & $\mathrm{M}=\mathrm{R}=2 \mathrm{phM}=\mathrm{PC}(\mathrm{VL})=\mathrm{PT}(\mathrm{VL})=\mathrm{PS}(\mathrm{VL})$ & $1 . . \mathrm{n}(\mathrm{L}, \mathrm{VL})$ & $2(\mathrm{~V} ; \mathrm{L})$ \\
\hline 12 & $\mathrm{M}=\mathrm{R}=2 \mathrm{phM}=\mathrm{PC}(\mathrm{VV})=\mathrm{PT}(\mathrm{P}: \mathrm{VV})=\mathrm{PS}(\mathrm{VV})$ & 1..n $(\mathrm{V}, \mathrm{VV})$ & $2(\mathrm{~V} ; \mathrm{V})$ \\
\hline 13 & $\mathrm{M}=\mathrm{C}=2 \mathrm{phM}=\mathrm{PC}(\mathrm{VL})=\mathrm{PT}(\mathrm{VL})$ & $1 . . \mathrm{n}(\mathrm{L}, \mathrm{VL})$ & $1(\mathrm{~V} / \mathrm{L})$ \\
\hline 14 & $\mathrm{M}=\mathrm{H}=2 \mathrm{phM}=\mathrm{PC}(\mathrm{VL})=\mathrm{PT}(\mathrm{VL})$ & $1 . . \mathrm{n}(\mathrm{L}, \mathrm{VL})$ & $1(\mathrm{~V} / \mathrm{L})$ \\
\hline 15 & $\mathrm{M}=\mathrm{H}=\mathrm{R}=2 \mathrm{phM}=\mathrm{PC}(\mathrm{VL})=\mathrm{PT}(\mathrm{P}: \mathrm{VL})$ & 1..n(L,VL) & $1(\mathrm{~V} / \mathrm{L})$ \\
\hline 16 & $\mathrm{M}=\mathrm{C}=\mathrm{R}=2 \mathrm{phM}=\mathrm{PC}(\mathrm{VL})=\mathrm{PT}(\mathrm{P}: \mathrm{VL})$ & 1..n(L,VL) & $1(\mathrm{~V} / \mathrm{L})$ \\
\hline 17 & $\mathrm{M}=\mathrm{C}=\mathrm{R}=2 \mathrm{phM}=\mathrm{PC}(\mathrm{VL})=\mathrm{PT}(\mathrm{P}: \mathrm{VL})=\mathrm{PS}(\mathrm{VL})$ & $1 . . \mathrm{n}(\mathrm{L}, \mathrm{VL})$ & $2(\mathrm{~V} ; \mathrm{L})$ \\
\hline 18 & $\mathrm{M}=\mathrm{H}=\mathrm{R}=2 \mathrm{phM}=\mathrm{PC}(\mathrm{VL})=\mathrm{PT}(\mathrm{P}: \mathrm{VL})=\mathrm{PS}(\mathrm{VL})$ & $1 . . \mathrm{n}(\mathrm{L}, \mathrm{VL})$ & $2(\mathrm{~V} ; \mathrm{L})$ \\
\hline 18 & $\mathrm{M}=\mathrm{H}=\mathrm{R}=2 \mathrm{phM}=\mathrm{PC}(\mathrm{VL})=\mathrm{PT}(\mathrm{VL})=\mathrm{PS}(\mathrm{VL})$ & 1..n(L,VL) & $2(\mathrm{~V} ; \mathrm{L})$ \\
\hline 20 & $\mathrm{M}=\mathrm{C}=\mathrm{R}=2 \mathrm{phM}=\mathrm{PC}(\mathrm{VL})=\mathrm{PT}(\mathrm{VL})=\mathrm{PS}(\mathrm{VL})$ & 1..n(L,VL) & $2(\mathrm{~V} ; \mathrm{L})$ \\
\hline 21 & $\mathrm{M}=\mathrm{H}=\mathrm{R}=2 \mathrm{phM}=\mathrm{PC}(\mathrm{VV})=\mathrm{PT}(\mathrm{P}: \mathrm{VV})=\mathrm{PS}(\mathrm{VV})$ & $1 . . \mathrm{n}(\mathrm{L}, \mathrm{VV})$ & $2(\mathrm{~V} ; \mathrm{V})$ \\
\hline 22 & $\mathrm{M}=\mathrm{C}=\mathrm{R}=2 \mathrm{phM}=\mathrm{PC}(\mathrm{VV})=\mathrm{PT}(\mathrm{P}: \mathrm{VV})=\mathrm{PS}(\mathrm{VV})$ & 1..n(V,VV) & $2(\mathrm{~V} ; \mathrm{V})$ \\
\hline 23 & $\mathrm{M}=2 \mathrm{phM}=\mathrm{PC}(\mathrm{VL})=\mathrm{PT}(\mathrm{P}: \mathrm{VL})=\mathrm{PS}(\mathrm{VL})$ & 1..n $(\mathrm{L}, \mathrm{VL})$ & $2(\mathrm{~V} ; \mathrm{L})$ \\
\hline 24 & $\mathrm{M}=2 \mathrm{phM}=\mathrm{PC}(\mathrm{VL})=\mathrm{PT}(\mathrm{P}: \mathrm{VV})=\mathrm{PS}(\mathrm{VV})$ & 1..n $(\mathrm{L}, \mathrm{VL})$ & $2(\mathrm{~V} ; \mathrm{L})$ \\
\hline 73 & $\mathrm{D}$ & $1(\mathrm{~L} ; \mathrm{VL}, \mathrm{V})$ & $1 . . \mathrm{n}(\mathrm{L} / \mathrm{V} / \mathrm{VL})$ \\
\hline
\end{tabular}


From the system properties; transesterification reaction and limiting equilibrium reaction; and the available SPBs reaction and separation can occur simultaneously within an SPB, for example, SPB 18 (see Table 17) indicates $\mathrm{M}=\mathrm{H}=\mathrm{R}=2 \mathrm{phM}=\mathrm{PC}(\mathrm{VL})=\mathrm{PT}(\mathrm{VL})=\mathrm{PS}(\mathrm{VL})$. Therefore, using this option provided by the SPB (at the phenomena level) and knowledge that simultaneous reaction and separation task (see Table 15, for example, for limiting equilibrium) increases the raw materials conversion, the possibility exists for combining the reaction and separation. Therefore, the following task is identified: Reaction-separation task. The task and phenomena-based flowsheets are shown in Figure 15.

Figure 15. Task and phenomena based flowsheets for combining reaction and separation tasks.

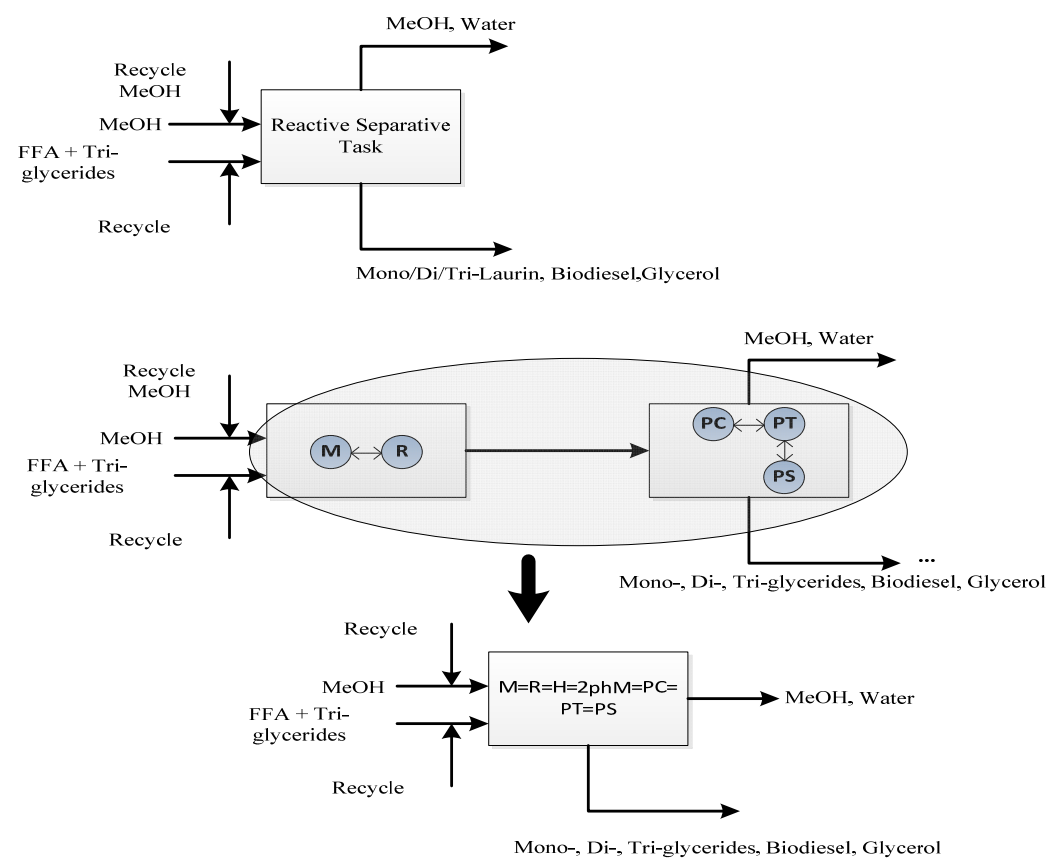

However, SPB 18 cannot by itself fulfill process requirements because it does not include complete separation of the raw materials/products, which can then be recycled to increase the raw material conversion (which is desired). Therefore, more SPBs are added to the current SPB, which now includes non-reactive SPBs and this can now be termed as an operation and is shown in Figure 16.

Figure 16. The phenomena building block as a result of connecting SPBs.

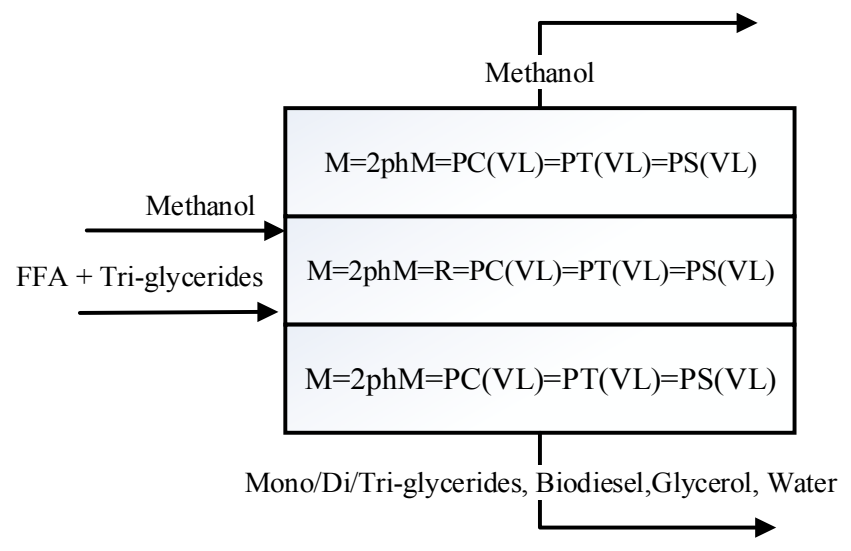


Figure 17 shows the operation, which is then transferred to the final flowsheet to replace the reaction and separation after it, in the base case design. The operation has the following characteristics: (a) simultaneous reaction and separation of raw materials and products, (b) the raw materials and products can now be purified for obtaining the raw materials for recycle and the product for collection. However in order to have the existence of VL due to the difference in boiling points of the raw materials and products, heating and cooling are added at the bottom and top of the operation, respectively.

Figure 17. The generated intensified unit operations to combine reaction and separation task: Reactive distillation.

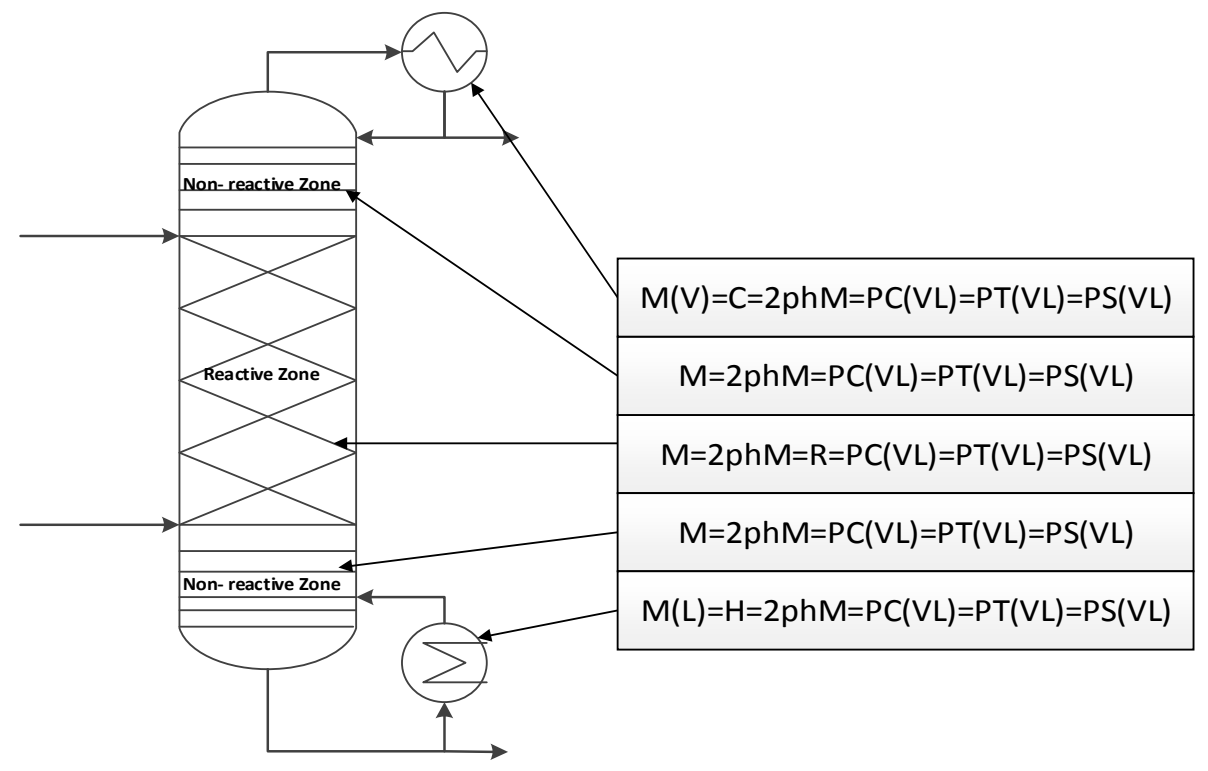

It was found that pure methanol could be obtained at the top of this operation but the biodiesel product at the bottom (besides having glycerol) also has some methanol, which has also been shown by Simasatitkul et al. [9] based on the analysis of the ternary reactive phase diagram. Therefore, the final operation, which fulfills the process requirements, must now be translated to a unit operation. This is done by using a knowledge base, which contains SPBs in terms of unit operations and the result found was a reactive distillation column presented in Figure 17.

\subsubsection{Step 3.5: Fast Screening Using Process Constraints}

This step is not applicable in the present application of the framework since an intensified unit operation was highlighted in the previous step that combines the reaction and separation tasks in the base case design. Generation of further alternatives and their screening has not been considered in this work.

\subsubsection{Step 3.6: Solve the Reduced Optimization Problem}

In order to check the feasibility of the proposed intensified operation (given in Step 3.4) for production of biodiesel and recovery of methanol; the reactive distillation column was simulated using rigorous models (Using Aspen Hysys process simulator). The total number of stages for this reactive distillation was found to be 6 including reboiler and condenser. Methanol and waste cooking oil are fed 
to the column from the second stage with a 10:1 mole ratio of methanol to triglycerides and FFA mixture after connecting all the other separation units in the flowsheet and recycle loops. The reflux ratio should be kept at a very low value since refluxing the water back to the column will consequently shift the equilibrium toward the reactants. Due to this, the separation section of the base case for the separation of methanol, biodiesel and glycerol was reused since the compounds within the stream entering this section is the same as the base case. The final flowsheet inclusive of an intensified unit operation (reactive distillation column) is given in Figure 18. Note that the controllability of the reactive distillation has not been investigated in this work and it is a subject for future studies. The optimality of this process alternative cannot be guaranteed unless all the possible alternatives are generated at the phenomena level and then screened to find the optimal solution. In this work, only the adjacent reaction and separation steps were targeted for intensification. However, it can be claimed that a more sustainable alternative has been found.

The most important performance criteria, including the sustainability metrics for the base case and the intensified alternative are given in Table 18. Note that, at this point of the work, the capital investment was not considered. However, we plan to include this in future studies where it will be shown that the payback time due to extra capital investments for the new intensified alternatives is very short due to the extra profits. Therefore, what are considered in this work are the performance metrics (inclusive of operational costs) and the LCA metrics. Looking at these metrics it can be seen that the objective function that was defined in Step 3.1 has been fulfilled.

Figure 18. Final flowsheet inclusive of an intensified unit operation which is a reactive distillation column.

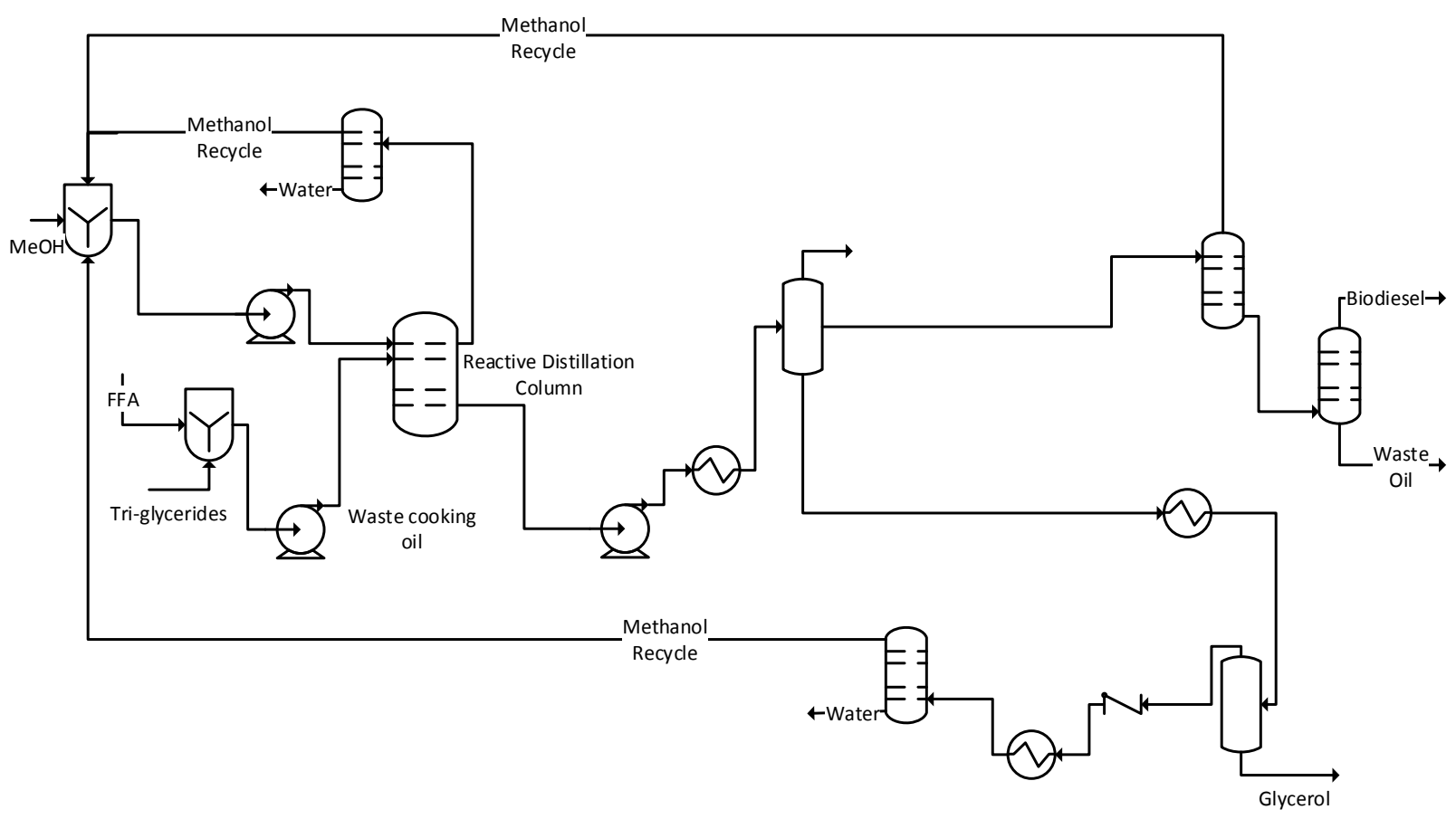

Comparing the base case design presented in Step 2.4, with the alternative design inclusive of PI given in Step 3.6 of this framework; it can be observed that the alternative design is more environmentally sustainable and economically profitable. It can be seen that in analyzing the base case 
design the reactor and the separation were identified as bottlenecks because they were in the path of the selected indicator (OP4; see Table 8). In terms of overcoming the bottlenecks that were identified through the intensification approach (see Table 15), the following process bottlenecks have been overcome as a result of combining the reaction and separation tasks: contact problem of raw materials in the reactor; high energy consumption (reduced utility costs as given in Table 18); limiting equilibrium was overcome due to the simultaneous removal of reactants and products; and difficult separation due to the low driving force has been to some extent overcome since pure methanol (raw materials) is recovered at the top of the reactive distillation column. It should also be noted, that all performance and LCA metrics have been either improved or remained neutral in the intensified process alternative.

Table 18. Comparison of the sustainability metrics in the base case design and the alternative design inclusive of PI.

\begin{tabular}{|c|c|c|c|c|}
\hline & Sustainability Metrics & $\begin{array}{c}\text { Base case } \\
\text { design }\end{array}$ & $\begin{array}{l}\text { Intensified } \\
\text { alternative }\end{array}$ & \%Improvement \\
\hline \multirow{10}{*}{ 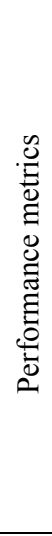 } & Total utility cost (\$/year) & $7,790,000$ & $4,660,000$ & 40.2 \\
\hline & Total energy consumption $(\mathrm{GJ} / \mathrm{h})$ & 119.163 & 73.104 & 38.6 \\
\hline & product/raw material $(\mathrm{kg} / \mathrm{kg})$ & 0.94 & 0.94 & 0 \\
\hline & Energy/ products $(\mathrm{GJ} / \mathrm{kg})$ & 0.0025 & 0.0017 & 32 \\
\hline & Net water added to the system $\left(\mathrm{m}^{3}\right)$ & 0 & 0 & 0 \\
\hline & Water for cooling/product $\left(\mathrm{m}^{3} / \mathrm{kg}\right)$ & 0.017 & 0.017 & 0 \\
\hline & Waste $/$ raw material $(\mathrm{kg} / \mathrm{kg})$ & 0.032 & 0.026 & 18.8 \\
\hline & Waste/products $(\mathrm{kg} / \mathrm{kg})$ & 0.034 & 0.028 & 17.6 \\
\hline & Hazardous raw material $/$ product $(\mathrm{kg} / \mathrm{kg})$ & 0 & 0 & 0 \\
\hline & Number of unit operations & 9 & 7 & 22 \\
\hline \multirow{12}{*}{ త্త } & Total carbon footprint ( $\mathrm{kg} \mathrm{CO}_{2}$ eq.) & 0.183 & 0.143 & 21.8 \\
\hline & HTPI-Human Toxicity Potential by Ingestion $\left(1 / \mathrm{LD}_{50}\right)$ & 0.51811 & 0.51111 & 0 \\
\hline & HTPE—Human Toxicity Potential by Exposure $\left(\mathrm{mg}_{\text {emiaion }} / \mathrm{m}^{3}\right)$ & 0.03558 & 0.03564 & 0 \\
\hline & GWP_-Global Warming Potential $\left(\mathrm{CO}_{2}\right.$ eq. $)$ & 0.55214 & 0.55241 & 0 \\
\hline & ODP-Ozone Depletion Potential (CFC-11 eq.) & $5.18 \times 10^{-9}$ & $5.18 \times 10^{-9}$ & 0 \\
\hline & PCOP_Photochemical Oxidation Potential $\left(\mathrm{C}_{2} \mathrm{H}_{2}\right.$ eq. $)$ & 0.04968 & 0.04976 & 0 \\
\hline & $\mathrm{AP}$-Acidification Potential ( $\mathrm{H}^{+}$eq. $)$ & 0.00010 & 0.00010 & 0 \\
\hline & ATP_Aquatic Toxicity Potential $\left(1 / \mathrm{LC}_{50}\right)$ & 0.00366 & 0.00366 & 0 \\
\hline & TTP-Terrestrial Toxicity Potential $\left(1 / \mathrm{LD}_{50}\right)$ & 0.51811 & 0.51111 & 0 \\
\hline & HTC (Benzene eq.)- - human toxicity (carcinogenic impacts) & 2062.7 & 1794.5 & 13 \\
\hline & HTNC (Toluene eq.) - human toxicity (non-carcinogenic impacts) & 1.3301 & 1.1795 & 11.3 \\
\hline & ET (2, 4-D eq.) - Fresh water ecotoxicity & 0.00525 & 0.00490 & 6.7 \\
\hline
\end{tabular}

LC50 is lethal concentration ( $\mathrm{mg}$ emission/kg fathead minnow); LD50 is one $\mathrm{kg}$ body weight of rat administered in milligrams of toxic chemical by mouth (mg emission/kg rat).

The question of uncertainty of data and/or model parameters on the final more sustainable design that has been obtained has not been investigated. Steimel et al. [38] have proposed a framework for optimizing flowsheet superstructures under uncertainty. A natural next step of this work would be to extend our computer aided framework for more sustainable design to include also uncertainty issues. 


\section{Conclusions}

In this work, a systematic framework for sustainable design and process intensification has been presented together with its application to a biodiesel production process. The framework is divided into 3 main parts: superstructure generation, base case design selection, and identification of sustainable design options. The framework is generic and can be applied to any chemical or biochemical process. In this work, it has been applied to biodiesel production, where the most promising process alternative in terms of economic, LCA and sustainability metrics was obtained in a systematic and efficient manner, taking into account the use of a number of different methods and tools and data from various sources. The final, intensified option was found by first setting a target for improvement on the selected base case and then by matching and evaluating alternatives to find the more sustainable design option. For the evaluation of alternatives, the measures used included sustainability metrics, economic potential and LCA factors. It was found that the alternative option for production of biodiesel is more economic and environmentally sustainable. Current and future work is extending the problem solution by considering all the chemicals present in the system and also by adding other likely feedstocks so that a truly optimal production process for biodiesel can be found. In this case, because the price and availability of the feedstock may vary in different geographical locations, this factor would also be added in the analysis. Therefore, using the framework and the collected data, different, more sustainable options for different geographical locations would be possible to generate without too much extra effort.

\section{References}

1. Escobar, J.C.; Lora, E.S.; Venturini, O.J.; Yáñez, E.E.; Castillo, E.F.; Almazan, O. Biofuels: Environment, technology and food security. Renew. Sustain. Energ. Rev. 2009, 13, 1275-1287.

2. Singh, A.; Pant, D.; Korres, N.E.; Nizami, A.S.; Prasad, S.; Murphy, J.D. Key issues in life cycle assessment of ethanol production from lignocellulosic biomass: Challenges and perspectives. Bioresour. Technol. 2010, 101, 5003-5012.

3. Kiss, A.A.; Bildea, C.S. A review of biodiesel production by integrated reactive separation technologies. J. Chem. Technol. Biotechnol. 2012, 87, 861-879.

4. International Energy Statistics. Available online: http://1.usa.gov/13Or0Bn (accessed 6 March 2013).

5. Biomass Research \& Development Initiative. Available online: http://www.esd.ornl.gov/eess/ (accessed 1 June 2013).

6. Lam, M.; Lee, K.; Mohamed, A. Homogenoues, heterogenous and enzymatic catalys for transesterification of high free fatty acid oil (waste cooking oil) to biodiesel: A review. Biotechnol. $A d v$. 2010, 28, 500-518.

7. Talebian-Kiakalaieh, A.; Amin, N.A.S.; Mazaheri, H. A review on novel processes of biodiesel production from waste cooking oil. Appl. Energ. 2013, 104, 683-710.

8. Leung, D.; Wu, X.; Leung, M. A review on biodiesel production using catalyzed transesterification. Appl. Energ. 2010, 87, 1083-1095. 
9. Simasatitkul, L.; Arpornwichanop, A.; Gani, R. Design methodology for bio-based processing: Biodiesel and fatty alcohol production. Comput. Chem. Eng. 2013, doi:10.1016/ j.compchemeng.2013.01.018.

10. Carvalho, A.; Gani, R.; Matos, H. Design of sustainable chemical processes: Systematic retrofit analysis generation and evaluation of alternatives. Process Saf. Environ. Prot. 2008, 86, 328-346.

11. Carvalho, A.; Matos, H.A.; Gani, R. Design of batch operations: Systematic methodology for generation and analysis of sustainable alternatives. Comput. Chem. Eng. 2009, 33, 2075-2090.

12. Carvalho, A.; Matos, H.A.; Gani, R. SustainPro-A tool for systematic process analysis, generation and evaluation of sustainable design alternatives. Comput. Chem. Eng. 2013, 50, 8-27.

13. Lutze, P.; Babi, D.K.; Woodley, J.M.; Gani, R. A phenomena based methodology for process synthesis incorporating process intensification. Ind. Eng. Chem. Res. 2013, 52, 7127-7144.

14. Yuan, Z.; Chen, B.; Gani, R. Applications of process synthesis: Moving from conventional chemical processes towards biorefinery processes. Comput. Chem. Eng. 2013, 49, 217-229.

15. West, A.H.; Posarac, D.; Ellis, N. Assessment of four biodiesel production processes using HYSYS. Plant. Bioresour. Technol. 2008, 99, 6587-6601.

16. Martín, M.; Grossmann, I.E. Simultaneous optimization and heat integration for biodiesel production from cooking oil and algae. Ind. Eng. Chem. Res. 2012, 23, 7998-8014.

17. Karunanithi, A.T.; Achenie, L.E.K.; Gani, R. A new decomposition-based computer-aided molecular/mixture design methodology for the design of optimal solvents and solvent mixtures. Ind. Eng. Chem. Res. 2005, 44, 4785-4797.

18. Jaksland, C.A.; Gani, R.; Lien, K.M. Separation process design and synthesis based on thermodynamic insights. Chem. Eng. Sci. 1995, 50, 511-530.

19. Gani, R.; Bek-Pedersen, E. Simple new algorithm for distillation column design. AIChE J. 2000, 46, 1271-1274.

20. Saengwirun, P. ECON: A Software for Cost Calculation and Economic Analysis. M.S. Thesis, Chulalongkorn University, Bangkok, Thailand, 2011.

21. Peters, M.S.; Timmerhaus, K.; West, R. Plant Design and Economics for Chemical Engineers; McGraw-Hill: Singapore, 2004.

22. Kalakul, S. Development of Software for Life Cycle Assessment. M.S. Thesis, Chulalongkorn University, Bangkok, Thailand, April 2013.

23. PRO/II User's Guide; Simulation Sciences, Inc.: Brea, CA, USA, 2011.

24. Aspen HYSYS User's Guide; Aspen Technology, Inc.: Burlington, MA, USA, 2009.

25. Marrero, J.; Gani, R. Group-contribution based estimation of pure component properties. Fluid Phase Equilbria 2001, 183, 183-208.

26. Zhang, Y.; Dubé, M.A.; McLean, D.D.; Kates, M. Biodiesel production from waste cooking oil: 1. Process design and technological assessment. Bioresour. Technol. 2003, 89, 1-16.

27. Sotoft, L.F.; Rong, B.; Christensen, K.V.; Norddahl, B. Process simulation and economical evaluation of enzymatic biodiesel production plant. Bioresour. Technol. 2010, 101, 5266-5274.

28. Darnoko, D.; Cheryan, M. Kinetic of palm oil transesterification in a batch reactor. J. Am. Oil Chem. Soc. 2000, 77, 1263-1267. 
29. Wang, Y.; Ou, S.; Liu, P.; Xue, F.; Tang, S. Comparison of two different processes to synthesize biodiesel by waste cooking oil. J. Mol. Catal. A 2006, 252, 107-112.

30. Lou, W.; Zong, M.; Duan, Z. Efficient production of biodiesel from high free fatty acid-containing waste oils using various carbohydrate-derived solid acid catalysts. Bioresour. Technol. 2008, 99, 8752-8758.

31. Nárvaez, P.; Rincón,S.; Sánchez, F. Kinetic of palm oil methanolysis. J. Am. Oil Chem. Soc. 2007, 87, 971-977.

32. Jegannathan, K.; Seng, C.; Ravindra, P. Economic assessment of biodiesel production: Comparison of alkali and biocatalyst processes. Renew. Sustain. Energ. Rev. 2011, 15, 745-751.

33. Bokade, V.; Yadav, G. Transesterification of edible and nonedible vegetable oils with alcohols over heteropolyacids supported on acid-treated clay. Ind. Eng. Chem. Res. 2009, 48, 9408-9415.

34. Chew, Y.; Chua, L.; Cheng, K.; Sarmidi, M.; Aziz, R.; Lee, C. Kinetic study on the hydrolysis of palm olein using immobilized lipase. Biochem. Eng. J. 2008, 39, 516-520.

35. Edgar, L.; Yijun, L.; Dora, L.; Kaewta, S.; David, B.; Goodwin, J.G. Synthesis of biodiesel via acid catalysis. Ind. Eng. Chem. Res. 2005, 44, 5353-5363.

36. Ma, F.; Hanna, M.A. Biodiesel production. Bioresour. Technol. 1999, 70, 1-15.

37. Karmakar, A.; Karmakar, S.; Mukherjee, S. Properties of various plant and animals feedstocks for biodiesel production. Bioresour. Tecnol. 2010, 101, 7201-7210.

38. Steimel, J.; Harrmann, M.; Schembecker, G.; Engell, S. A framework for modeling and optimization of process superstructures under uncertainty. Chem. Eng. Sci. 2013. doi:10.1016/j.ces.2013.04.052i.

(C) 2013 by the authors; licensee MDPI, Basel, Switzerland. This article is an open access article distributed under the terms and conditions of the Creative Commons Attribution license (http://creativecommons.org/licenses/by/3.0/). 